\title{
Battery storage systems: An economic model-based analysis of parallel revenue streams and general implications for industry
}

\author{
Braeuer, Fritz; Rominger, Julian; McKenna, Russell; Fichtner, Wolf
}

Published in:

Applied Energy

Link to article, DOI:

10.1016/j.apenergy.2019.01.050

Publication date:

2019

Document Version

Peer reviewed version

Link back to DTU Orbit

Citation (APA):

Braeuer, F., Rominger, J., McKenna, R., \& Fichtner, W. (2019). Battery storage systems: An economic modelbased analysis of parallel revenue streams and general implications for industry. Applied Energy, 239, 14241440. https://doi.org/10.1016/j.apenergy.2019.01.050

\section{General rights}

Copyright and moral rights for the publications made accessible in the public portal are retained by the authors and/or other copyright owners and it is a condition of accessing publications that users recognise and abide by the legal requirements associated with these rights.

- Users may download and print one copy of any publication from the public portal for the purpose of private study or research.

- You may not further distribute the material or use it for any profit-making activity or commercial gain

- You may freely distribute the URL identifying the publication in the public portal 


\title{
Battery Storage Systems: an economic model-based analysis of parallel revenue streams and gen- eral implications for industry
}

Fritz Braeuer*,+49 721608 44555, fritz.braeuer@kit.edu
Julian Rominger, +49 721 9654-556, $\underline{\text { rominger@fzi.de }}$
Russell McKenna ${ }^{\#},+45467751$ 59, rkenna@dtu.dk
Wolf Fichtner*, +49 721608 44460, wolf.fichtner@kit.edu

* Chair of Energy Economics, Institute for Industrial Production (IIP), Karlsruhe Institute of Technology (KIT), Karlsruhe, Germany

${ }^{\circ} \mathrm{FZI}$ Forschungszentrum Informatik, Karlsruhe, Germany

\# DTU Management Engineering, Technical University of Denmark (DTU), Kgs. Lyngby, Denmark

\begin{abstract}
This paper evaluates the economic potential of energy flexibility in 50 different German small and medium sized enterprises (SMEs) through the installation of a battery storage system (BSS). The central innovation lies in the possibility of pursuing multiple revenues streams simultaneously: peak shaving, provision of primary control reserve (PCR) and energy-arbitrage-trading through intraday and day-ahead markets. The energy system of an industrial manufacturing plant is modelled as a linear program (LP) with a 15-minute resolution. The model offers the option to invest in BSSs with different capacities, with the objective of minimizing the overall cost and identifying the optimal size of the BSS. The results show that none of these three revenue streams individually is economically attractive, but when combined, all three together can achieve profitability for some companies, whereby the majority of the cash flow comes from peak shaving and PCR. With a fixed BSS capacity of $500 \mathrm{kWh}$, the Net Present Value (NPV) varies from a minimum of $-350,000 €$ for just arbitrage up to about $200,000 €$ for all three use cases in parallel. In the case of a variable BSS capacity, the capacity varies up to $1200 \mathrm{kWh}$ and the Profitability Index (the ratio of investment to NPV) varies from 0.06 to 0.31 . Under current German market conditions, arbitrage trading contributes only marginally to the profitability, as the price spreads are too small to justify stronger battery degradation. The paper also identifies various load indicators from the analysis of the demand profile that support the evaluation of a BSS in Industry. A stepwise linear regression reveals a moderate dependency of the BSS profitability on two newly developed load indicators. Future work should focus on a more detailed depiction of the battery's technical behaviour and increasing the sample size to improve the statistical significance of the results.
\end{abstract}

\section{Keywords:}

Battery Storage System; Industry; Primary Control Reserve; Energy Market; Peak shaving; Load Indicator 


\begin{tabular}{|c|c|c|c|c|}
\hline $\begin{array}{l}\text { Nomenclature } \\
\text { Acronyms }\end{array}$ & & Variables & Unit & \\
\hline BSS & Battery storage system & $x_{\text {grid }}$ & kWh & Electrical energy flow from and to grid \\
\hline PCR & Primary control reserve & $x_{x, y}$ & kWh & Electrical energy flow from $x$ to $y$ \\
\hline SME & $\begin{array}{l}\text { Small and medium sized enter- } \\
\text { prises }\end{array}$ & $x_{B S S, t o t}$ & kWh & Energy in-flow in BSS per year \\
\hline LP & Linear program & $P_{P C R}^{w}$ & MW & Amount of provided for PCR per week \\
\hline NPV & Net present value & $P_{x, y}$ & MW & Electrical power flow from $x$ to $y$ \\
\hline $\mathrm{PI}$ & Profitability index & $P_{\text {peak }}$ & MW & Peak power from grid per year \\
\hline PP & Payback period & $\mathrm{l}_{\mathrm{BSS}}^{\mathrm{q}, \mathrm{h}, \mathrm{w}}$ & kWh & Storage level of BSS \\
\hline U1 - U6 & $\begin{array}{l}\text { Use case, combination of revenue } \\
\text { streams }\end{array}$ & $C_{e l}^{h, w}$ & $€$ & Cost and revenue for electricity trading \\
\hline DSM & Demand side management & $R_{P C R}^{w}$ & $€$ & Revenue from PCR \\
\hline & & $C_{\text {peak }}$ & $€$ & Cost for power capacity \\
\hline Sets and indices & & $A_{B S S}$ & $€$ & Annuity payment for BSS \\
\hline q & Quarter hour & $\operatorname{cap}_{P C R}^{w}$ & kWh & Capacity of BSS reserved for PCR \\
\hline $\mathrm{h}$ & Hour & $\operatorname{cap}_{B S S}$ & kWh & Installed capacity of BSS \\
\hline $\mathrm{w}$ & Week & cap $_{B S S, \text { aged }}$ & kWh & $\begin{array}{l}\text { Invested capacity of BSS with battery deg- } \\
\text { radation }\end{array}$ \\
\hline grid & Electricity grid & $\operatorname{cap}_{a d d, l}$ & kWh & $\begin{array}{l}\text { Additional capacity invest due to storage } \\
\text { level degradation }\end{array}$ \\
\hline BSS & Battery storage system & cap $_{\text {red }, c y c l}$ & kWh & $\begin{array}{l}\text { Reduced capacity invest due to unex- } \\
\text { ploited cycle life }\end{array}$ \\
\hline prod & Production process & $C F_{\text {tot }}$ & $€$ & Total cash flow per year \\
\hline arb & Arbitrage trading & $C F_{x}$ & $€$ & Cash flow from revenue stream $\mathrm{x}$ \\
\hline peak & Peak shaving & & & \\
\hline PCR & Primary control reserve & Parameters & Unit & \\
\hline old & Before installation of BSS & $D_{x, \text { prod }}$ & kWh & Electrical energy demand of production \\
\hline new & After installation of BSS & $D_{P, \text { prod }}$ & $\mathrm{MW}$ & Electrical power demand of production \\
\hline $\mathrm{i}$ & 15-min time step in a day & $L T_{c a l}$ & years & Calendar lifetime \\
\hline j & Day per year & $L T_{c y c l}$ & cycles & Cycle lifetime \\
\hline & & $p_{\text {ahead }}^{h, w}$ & $€ / \mathrm{kWh}$ & Electricity price on day-ahead market \\
\hline Load indicators & & $\mathrm{p}_{\text {intra }}^{\mathrm{q}, \mathrm{h}, \mathrm{w}}$ & $€ /$ kWh & Electricity price on intraday market \\
\hline$P_{M D}$ & Mean daily peak load & $p_{\text {peak }}$ & $€ / M W$ & Grid charges \\
\hline$P_{T o U}$ & Most frequent peak load interval & $p_{B S S}$ & $€ / K W h$ & Price for BSS capacity \\
\hline$P_{L F}$ & Daily peakyness & $p u f f_{P C R}$ & - & Puffer factor for PCR \\
\hline$P_{P o U}$ & Yearly period of use & $T_{P C R, \text { crit }}$ & $\mathrm{h}$ & Critical time threshold for PCR \\
\hline$P_{i, j}$ & Mean production load & $T$ & a & Number of annuities \\
\hline$E_{\text {peak }, i, j}$ & Peak energy & $i$ & $\%$ & Discount rate \\
\hline$E_{\text {above }}$ & Energy above peak threshold & & & \\
\hline$P_{\text {interval }, j}$ & Number of peak intervals per day & & & \\
\hline Peak $_{\text {integral }}$ & Peak integral & & & \\
\hline Peak $_{\text {above }}$ & Peak above & & & \\
\hline Peak $_{\text {interval }}$ & Peak interval & & & \\
\hline Peak $_{\text {density }}$ & Peak density & & & \\
\hline peak $_{\text {abil }}$ & Peak ability & & & \\
\hline
\end{tabular}

\section{Introduction}

The growing share of volatile renewable electricity is increasing the stress on the German electricity grid: electricity producers are asked to balance sudden power shortfalls on the supply side and distribution grid operators need to overcome an increasing number of congestions. To counter these challenges and generate higher flexibilities on the demand side, different market measures have been implemented. The market for ancillary services has been opened to a growing number of prequalified suppliers of balancing power. The feed-in tariffs for renewable energy have also 
been drastically reduced, which alongside the achievement of grid parity for some technologies such as photovoltaics (PV) encourages a higher rate of energy self-sufficiency. Furthermore, through grid service charges or bilateral agreements, industrial electricity consumers are motivated to shift their peak load [1,2].

Because of their high energy demand, industrial companies can profit from these novel flexibility measures. To provide these flexibilities, industrial energy consumers can choose to adapt their production processes to electricity or capacity prices with demand response measures. Especially individual energy intensive processes can be linked to energy prices [3]. In other cases electricity can be integrated as a time-dependent production factor into the production planning process $[4,5]$. On the other hand, for many producing companies these options offer no economic value, as their production systems are laid out to achieve the highest utilization of their machine capacities. Additionally, there are further regulatory and knowledge based hurdles for such demand response schemes [6].

An alternative to demand response is the installation of a battery storage system (BSS). A BSS provides a pseudoflexibility: a flexible electricity demand can be offered to grid operators and electricity markets via different revenue streams while the production remains unaffected. Like self-sufficiency-optimization, peak shaving or the provision of ancillary services, various marketing schemes for the flexibility from BSSs in industries have been individually examined $[7,8]$. However, one unique attribute of BSSs is the ability to follow different business models simultaneously [9]. Many publications mention this possibility $[10,11]$ but the potential has not yet been thoroughly studied. Only a few authors focus their studies on the potential of BSS following different revenue streams in parallel. 12 [12] run an hourly dispatch algorithm in a two phase simulation and divide the dispatch into a primary and secondary application (hierarchical order), focus on peak shaving, self-consumption, investment deferral and control reserve. This hierarchical order of revenue streams might underestimate the economic success of a BSS because of the time variability and interdependency of these different revenue streams. 13 [13] apply a similar hierarchical prioritization of the peak shaving revenue stream. They simulate the BSS dispatch under a sharing economy principle for different customers but focus on PV-self-consumption and restrict BSS charging from the grid. 14 [14] and 15 [15] apply similarly strict charging constraints . 14 [14] analyse the BSS's operation with a three stage hotelling rent approach considering energy markets and ancillary services. Their model constrains battery charging and discharging to once a day. 15 [15] apply an MILP to study the battery dispatch from the energy utilities' point of view, whereby the peak shaving potential is restricted through a fixed power limit. This reduced degree of freedom might severely diminish the economic potential of a peak shaving application. Instead the power limit should rather be a decision variable of the optimization model. 16 [16] optimize the battery dispatch for energy utilities in the U.S. They integrate different time layers in their model to expand their scope on intraday and day-ahead markets, ancillary services as well as virtual bidding products. 17 [17] develop an open-source MILP model to optimize capacity planning and unit commitment of the multi-commodity system of an industrial company with time-sensitive commodity prices and peak demand charges.

The general conclusion is that combining different revenue streams increases the profitability of the BSS but there is "still an idle potential for even more applications" [13]. The following deficiencies in studies about multiple revenue streams for BSS can be identified in the literature:

- No combination of all three revenue streams of arbitrage trading, peak shaving and PCR. 
- No actual parallelization of all revenue streams. In contrast, a hierarchical approach is used.

- No investigation of the influence of different industrial load profiles.

- $\quad$ No combination of battery dispatch and battery investment for parallel revenue streams.

Against this background, this paper evaluates the economic potential of energy flexibility in industrial companies through the installation of a BSS. The contribution of this paper is the modelling of three revenue streams, energy arbitrage trading, peak shaving and PCR, applied in parallel. Furthermore, through the study of 50 different German small and medium-sized enterprises (SMEs) the effect that the different revenue streams and different load profiles have on the profitability of a BSS-investment is shown. In addition, the paper identifies specific load indicators that explain the variation in profitability for different BSSs in industry. This paper focusses on the German energy and power markets applying current regulations and prices of the mentioned revenue streams. The two main research hypotheses are:

S1. Applying different use cases in parallel increases the profitability of a BSS in industry.

S2. Specific load indicators explain the variation in profitability of a BSS in industry.

To test these statements, we perform three analytical steps:

A1. Optimizing with fixed BSS capacity

A2. Optimizing with variable BSS capacity

A3. Stepwise linear regression of load indicators

To optimize the operation and size of a BSS, we model the industrial manufacturing plant as a linear program (LP). The optimization model offers the option to invest in BSSs with different capacities, with the objective of minimizing the overall cost. In A1, the installed capacity of the BSS is an exogenous parameter and all 50 companies install identical BSSs. The model identifies the optimal operation of the BSS for different use cases. We study six different use cases, which represent different combinations of the different revenue streams providing primary control reserve, peak shaving and arbitrage trading respectively. Thereby we are able to answer S1. To test S2 we perform A1 and $A 2$. For $A 2$, the model identifies the optimal capacity endogenously. As the BSS's capacity differs for all the 50 companies, we derive a profitability index (PI) for the individual systems. In $A 3$, we incorporate the $P I$ as the dependent variable in a stepwise multi-linear regression model. The independent variables are the different load indicators that describe the load profile characteristics of the 50 industrial companies. The resulting linear regression model identifies the key load indicators that have a significant influence on explaining the variation of the profitability of BSSs.

The paper is structured as follows. In section 2, we describe the different revenue streams and review related work. In section 3, we present the methodology for our analysis, the optimization model, the economic evaluation, the load indicators and the stepwise multi-linear regression. Section 4 gives an overview of employed data. Next, the results of our analysis are presented in section 5. The paper concludes in section 6. 


\section{Revenue streams}

This section describes the three revenue streams that we consider in our analysis and summarizes the state of the art in scientific publications. From this overview, we derive assumptions for our research hypothesis $S 1$ and $S 2$. The three revenues streams are the following:

1. Arbitrage trading (arb): Trading electricity on the day-ahead and intraday markets. Using the BSS to store electricity in times of low prices and using electricity in times of high prices or selling it on the market.

2. Providing power control reserve (PCR): Providing frequency containment or restoration reserve.

3. Peak shaving (peak): Considering capacity prices from grid operators as a fixed price on the maximum power consumption per year.

\subsection{Arbitrage trading}

Multiple publications discuss arbitrage trading as a revenue stream for BSSs. In arbitrage trading, the operator of a BSS can capitalize the time-dependent price differences on the electricity market. These price differences arise because of a deviation of the projected demand and supply of electricity. In such a case, the BSS-operator buys energy to charge its battery in times of low prices. Vice versa, he sells energy to discharge the BSS in times of high prices. In our study, we consider two German energy markets, the day-ahead auction and the intraday continuous market part of the EPEX-Spot market.

At the day-ahead auction at $12.00 \mathrm{pm}$, energy is mainly traded for hourly intervals of the next day. Energy is bought and sold at a market-clearing price. For the year 2017, this market-clearing price ranged between $-83.06 € / \mathrm{MWh}$ and $163.52 € / M W h$. The day-ahead market is the biggest market on the EPEX with 233 TWh traded in 2017 [18] and covers roughly 39 percent of the total energy consumed in Germany ${ }^{1}$.

In December 2011, the intraday continuous market was introduced in Germany to mitigate the growing influence of intermittent renewable energy sources. On this market, energy is continuously traded up to five minutes before delivery predominantly for each 15-minute interval. No uniform market-clearing price exists but instead a buy order is immediately executed if matched with a sell order and vice versa. This results in very volatile and dynamically changing prices, for 2017 ranging from -193.02 $€ / M W h$ and $329.8 € / \mathrm{MWh}^{2}$. With $54 \mathrm{TWh}$ in 2017 [20], the volume on this market is relatively small compared to the day-ahead market.

Many studies look at arbitrage trading as an applicable revenue stream for electrical storage systems. As arbitrage trading capitalizes on price differences, many authors emphasize the importance of large price spreads for a profitable use case [21-23]. Under current market conditions, the results of most studies show, that profitable arbitrage trading cannot be achieved yet [11]. Nonetheless, sinking battery cost and more volatile energy prices might drive the use of BSSs that follow an arbitrage trading scheme [24].

${ }^{1}$ The electricity consumption of Germany for the year 2017 accounted for 599 TWh ([19]).

2 The maximum price occurred on the 01.23 .2017 between 11.45 and 12.00 hours. The minimum price occurred on the 04.30.2017 between 17.00 and 17.15 hours. 
25 [25] and 16 [16] concluded that the volatility of energy prices increases if energy is traded close to real-time. The price is less elastic in longer time intervals, which underestimates the real-time demand imbalances and therefore underestimates the revenue potential of the arbitrage trading. Additionally, 26 [26] and 23 [23] conclude that the profitability depends strongly on the stochastic behaviour of load and price profiles.

Next to the strategic decision making, other authors focus on the real-time operation of BSS $[14,27]$ and optimal bidding strategies on real-time energy markets [28] to evaluate the implementation of profitable arbitrage trading. Nevertheless, the large number of uncertainties makes the profitability of the revenue stream questionable.

In conclusion, arbitrage trading is an intensively discussed revenue stream for BSSs. Because of the increasing amounts of renewable energies, authors predict growing price spreads on electricity markets. Together with sinking battery cost, this will strengthen the profitability of an arbitrage use case.

\subsection{Power control reserve (PCR)}

In order to maintain the grid operation frequency at its nominal value and therefore guarantee safe operation of connected devices, transmission system operators (TSOs) generally procure power control reserve - the flexibility of power devices to adjust their operation point. In Central Europe, the European Network of Transmission System Operators for Electricity (ENTSO-E) is in charge of dimensioning and operating said reserve, while national TSOs are in charge of its allocation, supervision and deployment. Three different control reserve products exist: Frequency containment reserve (FCR) is activated first and is technically most difficult to provide, after which automatic frequency restoration reserve (aFRR) and manual frequency restoration reserve ( $m F R R)$ are deployed [29](R. Hollinger et al. 2017). This paper focusses on the provision of FCR, as a regulatory framework for BSSs exist and it is the most profitable power control reserve. Currently, TSOs of six European country including Germany jointly procure FCR in a weekly auction. Remuneration is pay-as-bid, thus remuneration of bidders can vary for each auction.

FCR is provided proportional to the deviation of the current grid frequency from the nominal grid frequency. Traditionally, conventional power plants have provided FCR; however, generally only a small fraction of the rated power can be provided as fast response characteristics and symmetric provision of FCR is required. BSS inhibit transient response characteristics well suitable for the provision of FCR: the process of converting chemical into electrical energy and vice versa entails fast response times and high accuracy towards power signal resulting in little overshoot. While intermittent renewable energy sources already supply a great share of electricity supply, they hardly contribute to the provision of FCR [30]. Here, BSSs are a good alternative to reduce must-run capacities of fossil fuel power plants [31].

First ideas for BSSs to provide control reserve were published by 32 [32] for the insular power system of West Berlin. The successful operation of a test facility including a battery with a rated power of $14.4 \mathrm{~kW}$ by the local utility and transmission operator resulted in the operation of a lead-acid BSS with rated power of $17 \mathrm{MW}$ between 1987 and 1995 [33-35]. Due to high battery costs and short cycle lifetime only a limited number of mainly lead-acid BSS were built for the provision of FCR in the 1990s. Falling costs for lithium-ion BSS [36,37], high remuneration for the provision of FCR within Germany and specified operation criteria by the German TSOs [38,39] have resulted in a strong 
increase in the number of battery projects providing FCR $[40,41]$. This also led to an increase in publications concerning model-based approaches of BSS providing FCR. The majority of these models intend to decrease necessary schedule-based (dis-)charge events of battery systems providing FCR, which would result in higher operation costs [42-46].

From a technical standpoint, BSSs are well suited to provide FCR due to their power response characteristics.

To sum up, decreasing costs for batteries and a regulatory framework have led to a large number of realized projects within Germany in recent years. For simplicity reasons, this paper henceforth refers to the provision of power control reserve $(P C R)$ specifically referring to the provision of FCR.

\subsection{Peak shaving}

Peak shaving describes the use case where the peak load from the grid is reduced by the provision of energy from the BSS. Thereby, the maximum power drawn from the grid decreases and additional charges and fees by grid operators can be avoided. In Germany, distribution grid operators generally bill yearly capacity demand charges in $€$ per kW which account for the maximum power drawn from the grid over the course of one year in a 15-minute interval. Additionally, they consider the individual voltage level and the specific consumption characteristics: In the south of Germany, demand charges on the medium-voltage level range from $10.02 € / \mathrm{kW}$ for consumers with fewer full load hours $(<2500 \mathrm{~h})$ until $78.89 € / \mathrm{kW}$ for consumers with a high number of full load hours $(>2500 \mathrm{~h})^{3}$.

As peak shaving is a common use case for various real life applications [47-49] several studies have investigated the techno-economic feasibility of a BSS employing peak shaving. In most cases, peak shaving creates additional revenue for commercial and residential end-users $[6,50,51]$. Nonetheless, many researchers conclude that current battery prices are too high for BSSs to be cost effective when employing only peak shaving. 17 [17] evaluated a multi-energy system of different energy intensive industries considering variable energy prices and demand charges. They concluded that "for all scenarios with regular investment costs for electrical storage, batteries were not economically efficient [17]". 48 [48] investigated how an electrochemical storage could help an Italian super market to profit from low price and high price periods and to lower its demand charges. They considered different electrochemical storage technologies but concluded that none of them is cost effective under current prices. In contrast, 52 [52] and 53 [53] showed that for the specific application in a U.S. household, several BSSs can profitably provide peak shaving. 54 [54] concluded through their simulation that integrating energy storage systems to avoid high peak demand can be beneficial for utility companies as well as industrial energy consumers. This is in line with the findings of 55 [55] for the Australian setting.

17 [17] identified the magnitude of demand charges to be the most influential factor on the capacity choice of the storage unit. On the other hand, 23 [23] analyzed the energy system of a low-exergy building with stochastic PVProfiles and stated as a result that the volatility of the profiles has the highest influence on the sizing of the BSS. Adding to the optimal sizing problem, 56 [56] point out that the aging behavior of a BSS is an essential factor.

\footnotetext{
${ }^{3}$ Mean demand charges for 2016 in Baden-Würtemberg, Germany, according the Landesregierungsbehörde Baden-Württemberg, https://www.versorger-bw.de/landesregulierungsbehoerde/stromnetze/netzentgelte.html, checked 08.08.18 


\section{Methodology}

In this section, we describe the methodology for our analytical steps A1-A3. The first subsection describes the optimization model needed for $A 1$ and $A 2$ that models a BSS in an industrial production. The description focuses on the essential mathematical expressions for the reader to understand the conclusions of the paper. The model is fully explained in the Appendix. The subsequent subsection further elaborates the economic evaluation techniques that we apply on the results, the load indicators and the stepwise multi-linear regression model we need for $A 3$.

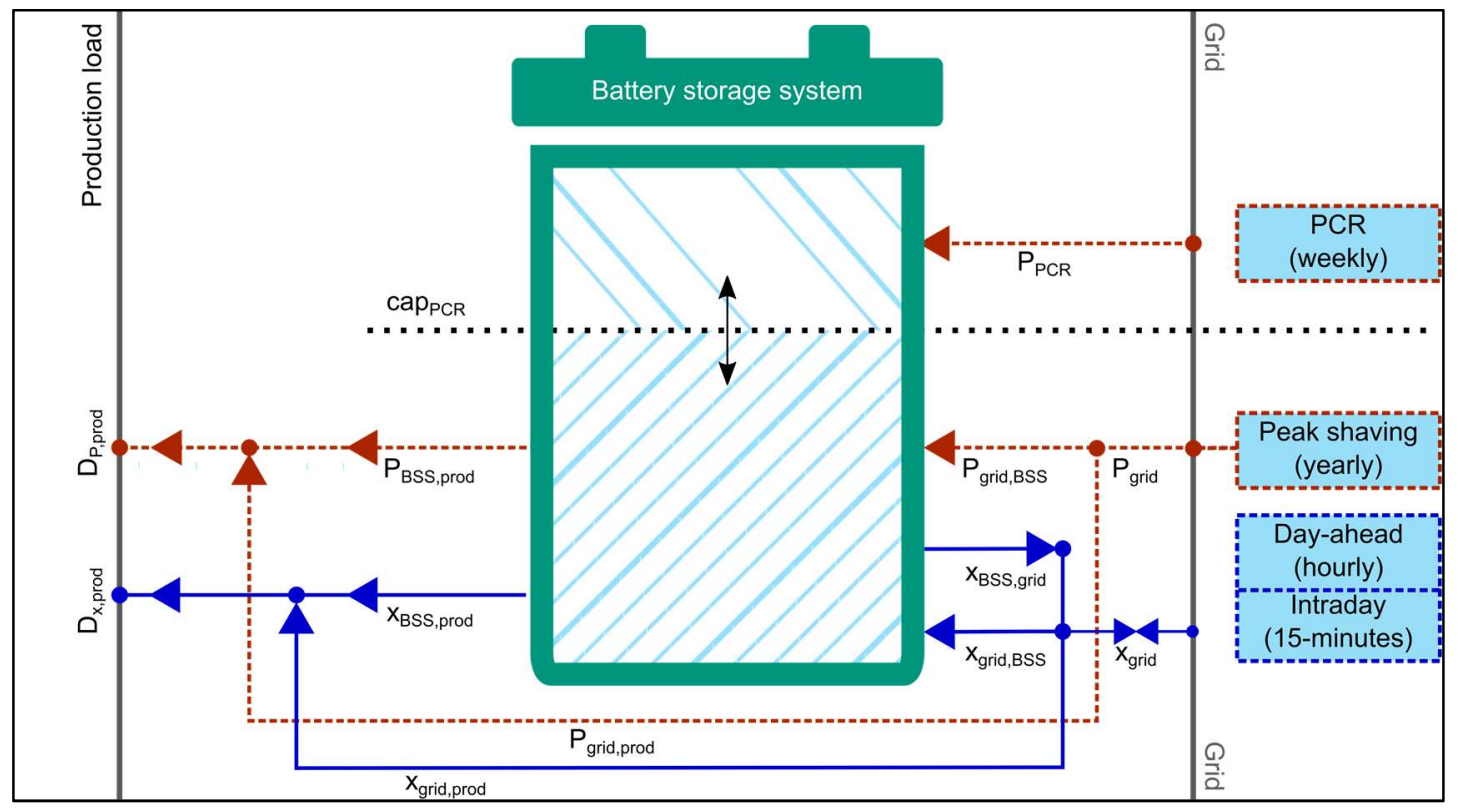

Figure 1: Graphical model schematic (parts of the schematic are creative commons designed by Freepik)

\subsection{The linear optimization model}

For the analytical steps $A 1$ and $A 2$, we implemented a linear problem (LP) in GAMS. Figure 1 shows graphically the structure of the energy model. In the schematic, $x$ indicates electrical energy flows and $P$ indicates electrical power flows. To investigate the economic benefits of a BSS, we consider the electrical energy and power demand $\left(D_{x, p r o d}\right.$ and $\left.D_{P, \text { prod }}\right)$ of an industrial production as an exogenous input parameter that needs to be satisfied at all times. The demand can be covered by electricity either directly from the grid $\left(x_{\text {grid,prod }}\right)$ or electricity previously stored in a BSS $\left(x_{B S S, p r o d}\right)$. The BSS can either draw electricity from the grid $\left(x_{\text {grid,BSS }}\right)$ or provide it to the grid $\left(x_{B S S, g r i d}\right)$. The electricity from and to the grid $\left(x_{\text {grid }}\right)$ can be traded on the hourly day-ahead market and the 15-minute intraday market. In analogy to the electricity flows, $P_{B S S \text {,prod }}, P_{\text {grid,BSS }}$ and $P_{\text {grid }}$ describe the power flows affecting the peak shaving potential. Furthermore, every week a portion of the BSS's capacity can be blocked to provide only PCR $\left(c a p_{P C R}\right)$. The energy system is evaluated over the course of one year (52 weeks) in 15-minute time intervals. The economic evaluation of the system is based on the year 2017. This year is considered as representative for all operating years. Furthermore, the authors assume perfect foresight for load profiles and price development on the dayahead and control reserve markets omitting the possibility of a bid rejection. 
The model is divided into three time intervals that result from the market design of the different flexibility markets. $q$ describes the quarter hourly time level on the intraday market, $h$ describes the hourly time level on the day-ahead market and $w$ describes the weekly time level, as PCR has to be reserved continuously for a whole week. These time levels are added up to one year as the peak shaving potential considers the peak load of one year. The decision variables of the model are the electrical energy flows in every time step, the power offered for PCR every week and the installed capacity of the BSS.

Formulating the constraints of the optimization model, the authors' aim is to reduce the complexity of the energy model while maintaining the actual depiction of energy and power flows. Therefore, this paper employs a LP-approach consisting of 349,441 equations, 262,133 variables and 1,118,261 non-zeros using the CPLEX-solver. With an average run time of around 9 minutes and 40 seconds, 400 model runs ${ }^{4}$ sum up to a total computation time of 2 days and 16 hours $^{5}$.

Table 1: Model assumptions

\begin{tabular}{|c|c|c|c|c|c|}
\hline Parameter & Unit & & Parameter & Unit & Parameter \\
\hline$\eta_{\text {in }}$ & $\%$ & 90 & $T_{P C R, c r i t}$ & Hours & 0.5 \\
\hline$\eta_{\text {out }}$ & $\%$ & 90 & $p u f f_{P C R}$ & - & 1.5 \\
\hline$d i s_{B S S}$ & $\% /$ month & 2 & $E_{P C R, \text { mean }}$ & $\mathrm{kWh} /$ week & 4889.7 \\
\hline EoL & $\%$ & 80 & Discount rate $i$ & $\%$ & 2 \\
\hline$L T_{\text {cal }}$ & years & 11 & Number of annuities $T$ & years & 11 \\
\hline$L T_{c y c l}$ & Cycles & 4000 & & & \\
\hline
\end{tabular}

Table 1 presents additional model assumptions. The charging efficiency, $\eta_{\text {in }}$, and discharging efficiency, $\eta_{\text {out }}$, is assumed with $90 \%$ where the selfdischarge is set to $2 \% /$ month. Additional technical assumptions, further discussed in subsection 3.1.3, are the end-of-life factor, $E o L=80 \%$, as well as a calendar lifetime, $L T_{c a l}$, of 11 years and a cycle lifetime, $L T_{c y c l}$, of 4000 cycles. Concerning PCR conditions, treated in subsection 3.1.2, the critical time that PCR, $T_{P C R \text {, crit }}$, must be provided for is a half hour, the PCR puffer factor, $p u f f_{P C R}$, is 1.5 and mean weekly charge due to PCR provision, $E_{P C R \text {,mean }}$, is $4,889.7 \mathrm{kWh} /$ week. The discount rate is $2 \%$ and the number of years $T$ considered for the annuities is 11 years.

\subsubsection{Objective functions}

The objective of the optimization problem is to minimize the overall system costs. This objective function is slightly modified for $A 1$ and $A 2$ as later described in Table 2 on page 13. The nomenclature in the following section describes electricity flow with an $x$ in $\mathrm{kWh}$, power with a $P$ in $\mathrm{MW}$ and the price with a small $p$. The expenditure as described

\footnotetext{
${ }^{4}$ For $A 1,50$ companies with 6 use cases add up to 300 model runs. Together with 50 model runs for $A 2$ this sums up to 350 model runs in total.

${ }^{5}$ The machine used for the computations utilizes $2.66 \mathrm{GHz}$ on 4 cores and $24 \mathrm{~GB}$ of RAM. 
in equation (1) is comprised of the cost and revenue from electricity trading, $C_{e l}^{h, w}$, the revenue from the provision of PCR, $R_{P C R}^{w}$, the charges for the yearly power capacity, $C_{\text {peak }}$, and the annuity payment of the BSS, $A_{B S S}$.

$$
\min f, \quad f=\sum_{w=1}^{52}\left(\sum_{h=1}^{168}\left(C_{e l}^{h, w}\right)-R_{P C R}^{w}\right)+C_{p e a k}+A_{B S S}
$$

Electricity is traded on the day-ahead market in hourly intervals and on the intraday market in 15-minute intervals. The first term in (2) multiplies the amount of electricity, $x_{\text {ahe }}^{h, w}$, traded on the day-ahead market with the price, $p_{\text {ahea }}^{h, w}$, on the day-ahead market for every hour in one year. $x_{\text {ahead }}^{h, w}$ can take positive values, implying electricity bought, or negative values, implying electricity sold. Accordingly, the second term in (2) describes the cost and revenue generated on the intraday market in one hour of the year. $x_{\text {intra }}^{q, h, w}$ represents the amount of electricity and $p_{\text {intra }}^{q, h, w}$ the price on the intraday market for every 15 -minute time interval. The general assumption for the use case arbitrage is that only one trade for each 15 -minute product is executed on the intraday market.

$$
C_{\text {el }}^{h, w}=x_{\text {ahead }}^{h, w} \cdot p_{\text {ahead }}^{h, w}+\sum_{q=1}^{4}\left(x_{\text {intra }}^{q, h, w} \cdot p_{\text {intra }}^{q, h, w}\right), \quad \forall h, w
$$

The revenue from PCR is calculated by the amount of provided power, $P_{P C R}^{w}$, multiplied by the weekly price for PCR, $p_{P C R}^{w}$, in equation (3).

$$
R_{P C R}^{w}=P_{P C R}^{w} \cdot p_{P C R}^{w}, \quad \forall w
$$

The capacity charges for the yearly peak power, $C_{\text {peak }}$, is result of maximal power drawn from the grid over the course of one year, $\mathrm{P}_{\text {peak }}$, times the capacity price, $p_{\text {peak }}$. This is shown by equation (4). Equation (5) determines $P_{\text {peak }}$ that is at least equal to any electricity flow from the grid, $x_{\text {grid }}^{q, h, w}$, during all 15 -minute time intervals of the year. As capacity charges are priced in $€ / M W a$ we multiply $x_{\text {grid }}^{q, h, w}$ with the term $\frac{4}{1000}$.

\begin{tabular}{|c|c|}
\hline$C_{\text {peak }}=P_{\text {peak }} \cdot p_{\text {peak }}$ & (4) \\
\hline$P_{\text {peak }} \geq x_{\text {grid }}^{q, h, w} \cdot \frac{4}{1000}, \quad \forall q, h, w$ & (5) \\
\hline
\end{tabular}

Equation (6) calculates the annuity payment for the investment of the BSS, $A_{B S S}$. It is the product of the cap $_{B S S, \text { aged }}$, the battery capacity to account for battery degradation, and the battery price, $p_{B S S}$. For this study, we only consider the energy capacity in $\mathrm{kWh}$. Last, this term is multiplied by the annuity factor $A F^{6}, \frac{1}{i}-\frac{1}{i \cdot(1+i)^{T}}$.

\footnotetext{
${ }^{6} A F$ refers to the annuity factor ([57]), ), considering a constant discount rate $i$ and number of annuities $T: A F=\frac{1}{i}-\frac{1}{i \cdot(1+i)^{T}}$.
} 


$$
A_{B S S}=\operatorname{cap}_{B S S, \text { aged }} \cdot p_{B S S} \cdot\left(\frac{1}{i}-\frac{1}{i \cdot(1+i)^{T}}\right)
$$

\subsubsection{PCR specifics}

The model accounts for the provision of PCR as one revenue stream but does not depict the actual electricity flow due to generally balanced reserve calls [58]. When the model chooses to provide PCR, one part of the BSS's capacity is blocked for any other BSS-application. Equations (7) and (8) describe this blocking. The model can only utilize residual parts of the BSS, the difference between the actual capacity of the BSS, cap $_{B S S}$, and the part of the capacity that is blocked for PCR, $c a p_{P C R}^{w}$. $c a p_{P C R}^{w}$ can be adapted weekly according to market prices for PCR. $c a p_{P C R}^{W}$ is always smaller than $\operatorname{cap}_{B S S}$, equation (9). Equation(10) ${ }^{7}$ defines $\operatorname{cap}_{P C R}^{w}$ as it multiplies the offered amount of PCR, $P_{P C R}^{w}$, by a puffer factor, $p u f f_{P C R}$. The value of this puffer factor is determined by the regulatory standards to meet the criteria for qualification to offer PCR. The value is usually greater than one.

\begin{tabular}{|c|c|}
\hline$x_{B S S, \text { in }}^{q, h, w}$ cap $_{B S S}-\operatorname{cap}_{P C R}^{w}, \quad \forall q, h, w$ & (7) \\
\hline$x_{B S,, \text { out }}^{q, h, w} \leq \mathrm{cap}_{B S S}-\operatorname{cap}_{P C R}^{w}, \quad \forall q, h, w$ & (8) \\
\hline $\operatorname{cap}_{P C R}^{w} \leq \mathrm{cap} p_{B S S}, \quad \forall w$ & (9) \\
\hline $\operatorname{cap}_{P C R}=\mathrm{puff}_{P C R} \cdot P_{P C R}^{w} \cdot 1000, \quad \forall w$ & (10) \\
\hline
\end{tabular}

Additionally, in order to qualify to provide PCR, the storage level, $l_{B S S}^{q, h, w}$, in the first period of the week must not be smaller than a critical lower bound, equation (11), and not be greater than a critical upper bound, equation (12). $l_{B S S}^{q, h, w}$ describes the storage level of the BSS for every time step in kWh. The critical threshold is defined by the amount of time measured in hours, $T_{P C R \text {,crit }}$, one needs to be able to continuously provide the maximum amount of PCR in one direction, positive or negative PCR [59]. We assume that an aggregator operates the BSS. Therefore, $P_{P C R}^{w}$ is modelled as a continuous variable.

\begin{tabular}{|c|c|}
\hline$l_{B S S}^{q, h, w} \leq c a p_{B S S}-\left(P_{P C R}^{w} \cdot T_{P C R, \text { crit }}\right), \quad \forall q, h, w$ & (11) \\
\hline$l_{B S S}^{q, h, w} \geq P_{P C R}^{w} \cdot T_{P C R, \text { crit }}, \quad \forall q, h, w$ & (12) \\
\hline
\end{tabular}

\subsubsection{Battery degradation}

To incorporate battery degradation into the model, we follow the approach of 60 [60]. They consider the end of life condition of the BSS as well the influence of the calendar and cycle life restrictions. In order to properly assess the economic performance of a BSS, 60 [60] account for these different aging effects by oversizing the initial BSS capacity the model invests in. Thereby, they guarantee that the BSS dispatch plan can be fulfilled until the end of life of the BSS. In this current study, we refer to the aged and oversized capacity as cap $_{B S S, \text { aged }}$.

The basis of the degradation formulations is the assumption that the end of life is reached at the end of calendar life and that the cycle life is fully exploited. At the end of life, the BSS can only utilize a portion of its initial capacity. This portion is described by the end of life factor, EoL. We assume the risk of operating the BSS beyond this point in time

\footnotetext{
7 The term is multiplied by the factor 1000 to convert from MW to $\mathrm{kW}$
} 
is economically unacceptable. The full calendar life can be reached as long as the average storage level is low. Higher storage levels reduce the calendar life. In contrast, if the cycle life is not fully exploited, this prolongs the BSS's calendar life. Thus, to guarantee that the installed capacity $\operatorname{cap}_{B S S}$ is fully accessible until the last day of operation the invested BSS capacity $c a p_{B S S, \text { aged }}$ needs to compensate the degradation effects. Equation (13) describes $\operatorname{cap}_{B S S, \text { aged }}$ and splits it into three terms. The first term considers the end of life condition of the BSS and the installed capacity, cap $_{B S S}$, needs to be oversized by $\frac{1}{E O L}$.

$$
\operatorname{cap}_{B S S, \text { aged }}=\frac{c a p_{B S S}}{E o L}+\operatorname{cap}_{a d d, l}-c_{\text {rap }, c y c l}
$$

The second term of equation (13) considers an additional capacity, $c a p_{a d d, l}$, to compensate the BSS degradation due to high storage levels of the BSS. Equation (14) states that $\operatorname{cap}_{a d d, l}$ is $\frac{1}{3}$ of the average storage level, $\mathrm{l}_{B S S}^{q, h, w}$, over the number of time intervals $N_{\text {intervall }}{ }^{8}$. The third term of equation (13), considers the fact that a not fully exploited cycle life results in a prolonged calendar life and $c a p_{\text {red,cycl }}$ reduces $c a p_{B S S, a g e d} . c a p_{\text {red,cycl }}$ is calculated in equation (15). Here, $x_{B S S, t o t}$ refers to the total amount of electricity that flows into the BSS over the course of one year. $x_{B S S, t o t}$ is multiplied by $L T_{c a l}$, the calendar lifetime, and divided by $L T_{c y c l}$, the cycle lifetime, to show the average electricity in-flow per cycle. Finally, the difference between $c a p_{B S S}$ and this average electricity in-flow per cycle is multiplied by the factor $\frac{1}{3} \cdot x_{B S S, t o t}$ is calculated in equation (16) and is the sum of the electricity in-flow for every time interval, $x_{B S S, i n}^{q, h, w}$, plus a weekly share of electricity in-flow due to PCR provision. As we do not model the actual electricity flow for PCR, we include a mean value $E_{P C R \text {,mean }}$ multiplied by the amount of power offered for PCR $P_{P C R}^{w} \cdot{ }^{10}$ Finally, we consider equation (17) to guarantee that the amount of electricity over the calendar life, $x_{B S S, t o t}$. $T L_{c a l}$, does not exceed the product of cycle life times BSS capacity.

\begin{tabular}{|c|c|}
\hline $\operatorname{cap}_{a d d, l}=\frac{1}{3} \cdot \sum_{w=1}^{52} \sum_{h=1}^{168} \sum_{q=1}^{4} l_{B S S}^{q, h, w} \cdot \frac{1}{N_{\text {intervall }}}$ & (14) \\
\hline $\operatorname{cap}_{\text {red }, \text { cycl }}=\frac{1}{3} \cdot\left(\operatorname{cap}_{B S S}-\left(x_{B S S, \text { tot }} \cdot \frac{L T_{\text {cal }}}{L T_{\text {cycl }}}\right)\right)$ & (15) \\
\hline$x_{B S S, \text { tot }}=\sum_{w=1}^{52}\left(\left(\sum_{h=1}^{168} \sum_{q=1}^{4} x_{B S S, \text { in }}^{q, h, w}\right)+P_{P C R}^{w} \cdot E_{P C R, \text { mean }}\right)$ & (16) \\
\hline$x_{B S S, t o t} \cdot T L_{c a l} \leq T L_{c y c l} \cdot c a p_{B S}$ & (17) \\
\hline
\end{tabular}

\footnotetext{
8 "It is a linear function derived from 61 ([61]), which states that an always fully charged SBS reduces its whole lifetime by about one third." ([60])

${ }^{9}$ The factor $\frac{1}{3}$ refers to 62 ([62]) and the result that the cycle life influences one third of the BSS's life time.

${ }^{10} E_{P C R, \text { mean }}$ is the mean amount of energy that a BSS providing $1 \mathrm{MW}$ of PCR had to charge per week in the year 2016 . We concluded this mean value from the frequency data of the year 2016. The unit is $k W h / M W$.
} 
With exemplary numbers, we illustrate the effect that the battery degradation constraints have on the annuity payment of the investment. For this example, the average storage level is assumed to be $100 \mathrm{kWh}$. This results in a $\mathrm{cap}_{a d d, l}$ of $33 \mathrm{kWh}$. Furthermore, under the assumption that the installed BSS capacity is $500 \mathrm{kWh}$, the example case utilizes roughly half the available charging cycles. This would add up to $x_{B S S, t o t}$ of around $90,000 \mathrm{kWh}$ and in a $c a p_{\text {red,cycl }}$ of $84 \mathrm{kWh}$. Consequently together with a EoL of $80 \%, c a p_{B S S, \text { aged }}$ would amount to $574 \mathrm{kWh}$. Thus, the installed capacity is oversized to compensate for the degradation effects. This increases the annuity payment, which is considered in the objective function, equation (1). It should be noted that a small number of utilized cycles leads to a $c_{\text {red,cycl }}$, which overcompensates the other degradation effects resulting in a cap $p_{B S S, \text { aged }}$ smaller than the installed cap $_{B S S}$. This translates into a fictive case where, because of the prolonged calendar life, the BSS is still usable after its end of life and the residual value of the BSS reduces the investment.

\subsubsection{Modifications for $A 1$ and $A 2$ and the different use cases}

In the analytical step $A 1$ and $A 2$, we investigate the economic potential of a BSS following different revenue streams in parallel. For this paper, we constructed six use cases, which represent either an individual revenue stream or a combination of different revenue streams in parallel. Considering the literature overview in this section and the current price level on the different markets, we assume that PCR will have the biggest effect on the profitability of the BSSs. Thus, for the parallel revenue stream cases PCR is the common option to generate revenue. Table 2 gives a detailed overview of the different use cases and their respective objective function. Equation (18) refers to $U 1$, where arbitrage trading generates the only revenue and expenses. U2 utilizes the battery to profit from peak shaving, equation (19). Equation (20) refers to U3 where the model only provides PCR and therefore only considers the $R_{P C R}^{h, w}$. U4 combines PCR and arbitrage trading and U5 combines PCR and peak shaving. Finally, U6 considers all three revenue streams, PCR, arbitrage trading and peak shaving.

Table 2: Name of the different use cases, the referred number and the modified objective function

\begin{tabular}{|c|c|c|c|}
\hline Use case & Name of the use case & Objective function & (18) \\
\hline U1 & Arbitrage & $\min f, f=\sum_{w=1}^{52}\left(\sum_{h=1}^{168}\left(C_{e l}^{h, w}\right)\right)+A_{B S S}$ & (19) \\
\hline U2 & Peak shaving & $\min f, f=C_{\text {peak }}+A_{B S S}$ & (20) \\
\hline U3 & PCR & $\min f, f=\sum_{w=1}^{52}\left(-R_{P C R}^{w}\right)+A_{B S S}$ & (21) \\
\hline U4 & PCR and arbitrage & $\min f, f=\sum_{w=1}^{52}\left(\sum_{h=1}^{168}\left(C_{e l}^{h, w}\right)-R_{P C R}^{h, w}\right)+A_{B S S}$ & (22) \\
\hline U5 & PCR and peak & $\min f, f=\sum_{w=1}^{52}-R_{P C R}^{w}+C_{p e a k}+A_{B S S}$ & (23) \\
\hline U6 & All of the above & $\min f, f=\sum_{w=1}^{52}\left(\sum_{h=1}^{168}\left(C_{e l}^{h, w}\right)-R_{P C R}^{h, w}\right)+C_{p e a k}+A_{B S S}$ & \\
\hline
\end{tabular}


As part of the overall cost, $A_{B S S}$ is considered for every objective function. For analytical step $A 1$, we compare the same BSS for the different industrial companies. Here, the BSS's capacity is an exogenous parameter. Therefore, $A_{B S S}$ depends only on the battery degradation. The essential difference for the analytical step $A 2$ is that $c a p_{B S S}$ is an endogenous variable. For $A 2$ we analyse only U6.

\subsection{Economic evaluation}

To evaluate the profitability of the BSS we calculate the net present value NPV, equation (24). The total cash flow of the system $C F_{t o t}$ of one year multiplied with the capital recovery factor ${ }^{11}, \frac{(1+i)^{T} \cdot i}{(1+i)^{T}-1}$, is subtracted with the investment for the BSS, $c a p_{B S S, \text { aged }}$ multiplied with the battery price $p_{B S S}$.

$$
N P V=C F_{t o t} \cdot\left(\frac{(1+i)^{T} \cdot i}{(1+i)^{T}-1}\right)-c a p_{B S S, a g e d} \cdot p_{B S S}
$$

$C F_{\text {tot }}$ refers to the cash flow of the considered revenue stream. The cash flow for arbitrage trading, $C F_{a r b}$, is the difference between the total cost for electricity without a BSS, $C_{e l, o l d}$, and with a newly installed BSS, $C_{e l, n e w}$.

$$
C F_{\text {arb }}=\sum_{h, w} C_{e l, o l d}^{h, w}-\sum_{h, w} C_{e l, n e w}^{h, w}
$$

The cash flow for peak shaving, $C F_{\text {peak }}$, describes the savings in capacity spending between the old peak, $P_{\text {peak,old }}$ without a BSS, and the new peak, $P_{\text {peak,new, }}$ multiplied with the capacity price, $p_{\text {peak }}$.

$$
C F_{\text {peak }}=\left(P_{\text {peak }, \text { old }}-P_{\text {peak }, \text { new }}\right) \cdot p_{\text {peak }}
$$

The cash flow for PCR provision, $C_{P C R}$, is the total revenue of PCR, $R_{P C R}$, over one year.

$$
C F_{P C R}=\sum_{w=1}^{52} R_{P C R}^{w}
$$

For the comparison of different investments, we calculate the profitability index PI, equation (18). The PI represents the NPV per invested Euro [57].

$$
P I=\frac{N P V}{c a p_{B S S, \text { aged }} \cdot p_{B S S}}
$$

\subsection{Load indicators}

In $A 3$, we want to identify the significant independent variables, the load indicators that influence the profitability of a BSS. These indicators illustrate the characteristics of the individual load profiles. [63] introduced three electrical parameters to characterize the domestic electricity demand. They describe $P_{M D}$ as the mean daily peak load, $P_{\text {Tou }}$ as

\footnotetext{
11 The capital recovery factor refers to the capital recovery factor, the inversion of the present value calculation method with constant annuities ([57]), considering a constant discount rate $i$ and number of annuities $T: C R F=\frac{(1+i)^{T} \cdot i}{(1+i)^{T}-1}$.
} 
the maximum time of use and $P_{L F}$ as the "daily peakyness". We expand on these parameters to compare the peak shaving potential of the different industrial load profiles.

$P_{M D}$ describes the mean daily peak load in MW over the period of one year, see equation (29). $P_{i, j}$ is the mean production load over 15 minutes in $\mathrm{MW}$ and $n$ is the number of 15 -minute time periods in one day. $m$ is the number of days per year.

$$
P_{M D}=\frac{1}{m} \sum_{j=1}^{m} \max \left\{P_{i, j}, 1 \leq i \leq n\right\}
$$

$P_{\text {Tou }}$ identifies the time interval of one day, $j_{\max }$, during which the peak load occurs. Equation (30) builds the mode over all days of one year. Thereby, $P_{\text {Tou }}$ shows the time interval where the peak load occurs most of the time.

$$
P_{\text {ToU }}=\operatorname{mode}\left\{j_{\max } \mid P_{j_{\max }}=\max \left\{P_{i, j}, 1+n(j-1) \leq i \leq n, 1 \leq j \leq m\right\}\right\}
$$

The third indicator of 63 [63] is $P_{L F}$, which they refer to as the "daily peakyness", see equation (31). First, the equation compares the mean to the peak load of one day. Then, the mean of the sum of this daily ratio results in $P_{L F}$. This is a measure to describe the continuity of a load profile.

$$
P_{L F}=\frac{1}{m} \sum_{j=1}^{m} \frac{\frac{1}{n} \sum_{i=1}^{n} P_{i, j}}{\max \left\{P_{i, j}, 1 \leq i \leq n\right\}}
$$

To describe the continuity, we use an additional load indicator that is already established in the field of energy economics: the yearly period of use, $P_{P o U}$, or full load hours, Equation (32). It compares the yearly energy demand to the yearly peak power demand and illustrates how many hours one would continuously draw energy from the grid if the power were held constant at its maximum. To make it more tangible, we divide this ratio by the number of hours per year resulting in a percentage of a year.

$$
P_{\text {PoU }}=\frac{\sum_{i=0}^{n \cdot m} \frac{P_{i}}{4}}{\max \left\{P_{i}, 1 \leq i \leq n \cdot m\right\}} \cdot \frac{1 a}{8760 h}
$$

To display the peak shaving potential, we developed four indicators, Peakintegral, Peakabove, Peakinterval and Peakdensity. Figure 2 gives a graphic explanation of these indicators. Peakintegral describes the ratio of the energy amount that is
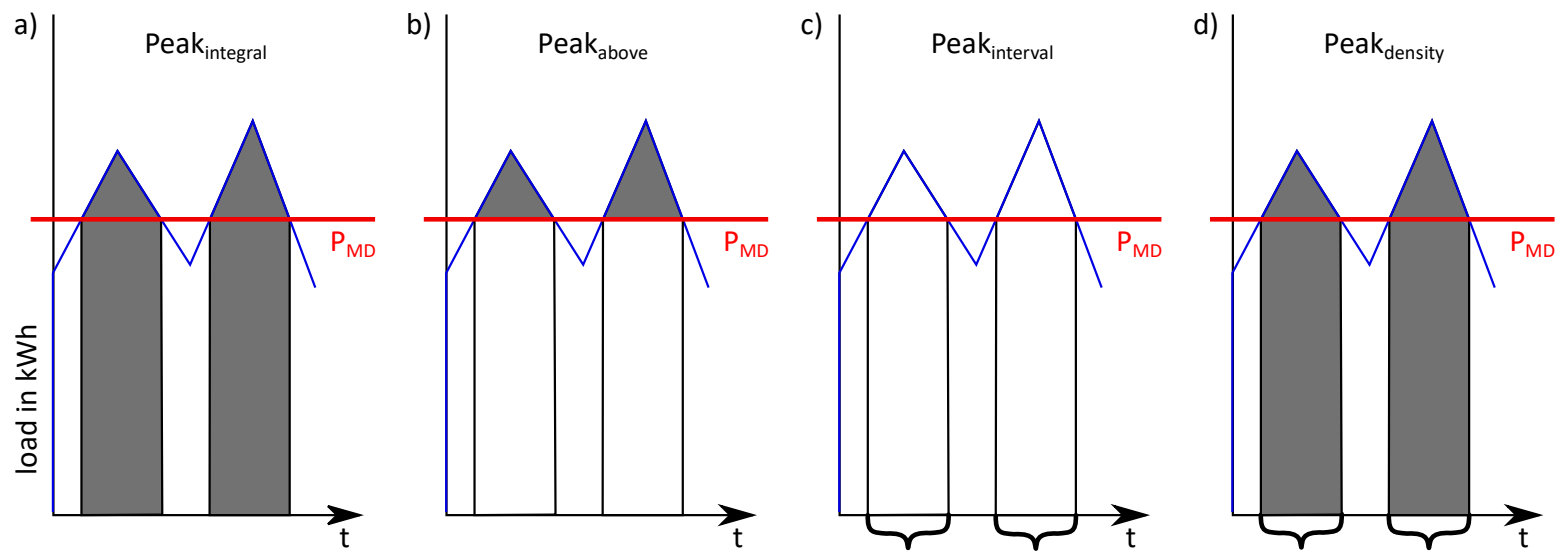

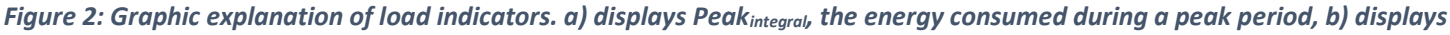

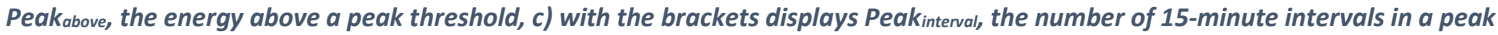

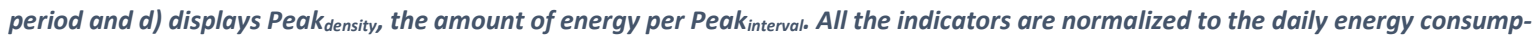
tion. 
consumed during a peak period to the total amount of energy consumed in one day as an average over the course of one year. Equation (33) gives the definition of a peak energy, $E_{p e a k, i, j}$. It accounts for all intervals where the load is greater than a fixed peak threshold in our case $P_{M D} . E_{p e a k, i, j}$ takes the value of $P_{i, j}$, if $P_{i, j} \geq P_{M D}$, or else the value 0 for all intervals of the day $n$ and all days of the year $m$. Furthermore, $P_{i, j}$ is multiplied by the term $\frac{24}{n}$ to derive energy and devided by the total amount of energy comsumed in one day. $E_{p e a k i, j}$ shows the percentage of the daily energy that is consumed during a peak interval.

$$
E_{\text {peak }, i, j}=\left\{\begin{array}{c}
\frac{P_{i, j} \cdot \frac{24}{n}}{\sum_{i}^{n} P_{i, j}}, \quad \text { if } P_{i, j} \geq P_{M D}, \quad 1 \leq i \leq n, 1 \leq j \leq m \\
0, \quad \text { if } P_{i, j}<P_{M D}
\end{array}\right.
$$

Equation (34) builds the mean of. $E_{p e a k, i, j}$ over one year to get the indicators Peakintegral, Figure 2 a).

$$
\text { Peak }_{\text {integral }}=\frac{1}{m} \sum_{j}^{m} \sum_{i}^{n} E_{\text {peak }, i, j}
$$

Accordingly, we get the indicator Peakabove, Figure 2 b). The only difference is that we consider the amount of energy that is above our threshold $P_{M D}$, see equation (35). In equation (36), Peakabove resembles the mean percentage of the daily-consumed energy that is above the peak threshold.

$E_{\text {above }, i, j}=\left\{\begin{array}{c|}\frac{\left(P_{\text {peak }, i, j}-P_{M D}\right) \cdot \frac{24}{n}}{\sum_{i}^{n} P_{i, j}}, \quad \text { if } \sum_{i}^{n} P_{i, j}>0 \\ 0, \quad \text { if } \sum_{i}^{n} P_{i, j}=0\end{array}\right.$

Peak $k_{\text {interval, }}$ Figure 2 c), accounts for the mean number of peak intervals per day. Equation (37) builds the cardinal

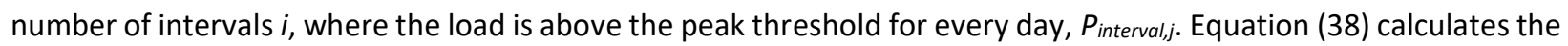

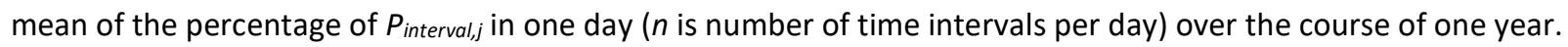

\begin{tabular}{|c|c|}
\hline$P_{\text {interval, } j}=\operatorname{card}\left(\left\{i \in \mathbb{N} \mid P_{i, j} \geq P_{M D}, \quad 1 \leq i \leq n\right\}\right)$ & (37) \\
\hline Peak $k_{\text {interval }}=\frac{1}{m} \sum_{j}^{m} \frac{P_{\text {interval, } j}}{n}$ & (38) \\
\hline
\end{tabular}

Last, Peakdensity, Figure $2 \mathrm{~d}$ ), describes how daily peak energy, $\sum_{i}^{n} E_{\text {peak }}, j^{j}$, is spread over the daily peak intervals, $P_{\text {intertval, }}$, see equation (39). It is shown as the mean over one year.

$$
\text { Peak }_{\text {density }}=\frac{1}{m} \sum_{j}^{m} \frac{\sum_{i}^{n} E_{\text {peak }, i, j}}{P_{\text {interval }, j}}
$$




\subsection{Stepwise multi-linear regression}

A stepwise multi-linear regression method is employed, to identify the significant independent variables that influence the profitability of a BSS. For the implementation, Matlab R2016a and the function stepwiselm ${ }^{12}$ us used. This function applies a bidirectional elimination algorithm. The selection criterion is the default $\mathrm{p}$-value $(p-v a l u e<$ 0.05 to enter, $p-$ value $<0.1$ to remove). The result of this method is a linear model, which includes all the significant independent variables $x_{i}$ to describe the dependent variable $y . b_{o}$ describes the $y$-intercept and $\beta_{i}$ the coefficient or the slope of the independent variable.

$$
y=\beta_{0}+\sum_{j}^{n} \beta_{j} \cdot x_{j}
$$

\section{Data}

\subsection{Load Data}

Table 3: Statistical overview of the load data

\begin{tabular}{|l|l|l|l|l|l|l|l|l|l|}
\hline $\begin{array}{l}\text { peak } \\
\text { load }\end{array}$ & $\boldsymbol{E}_{\text {total }}$ & $\boldsymbol{P}_{M D}$ & $\boldsymbol{P}_{\text {ToU }}$ & $\boldsymbol{P}_{L F}$ & $\boldsymbol{P}_{\text {PoU }}$ & Peak $_{\text {integral }}$ Peak & & & \\
\hline
\end{tabular}

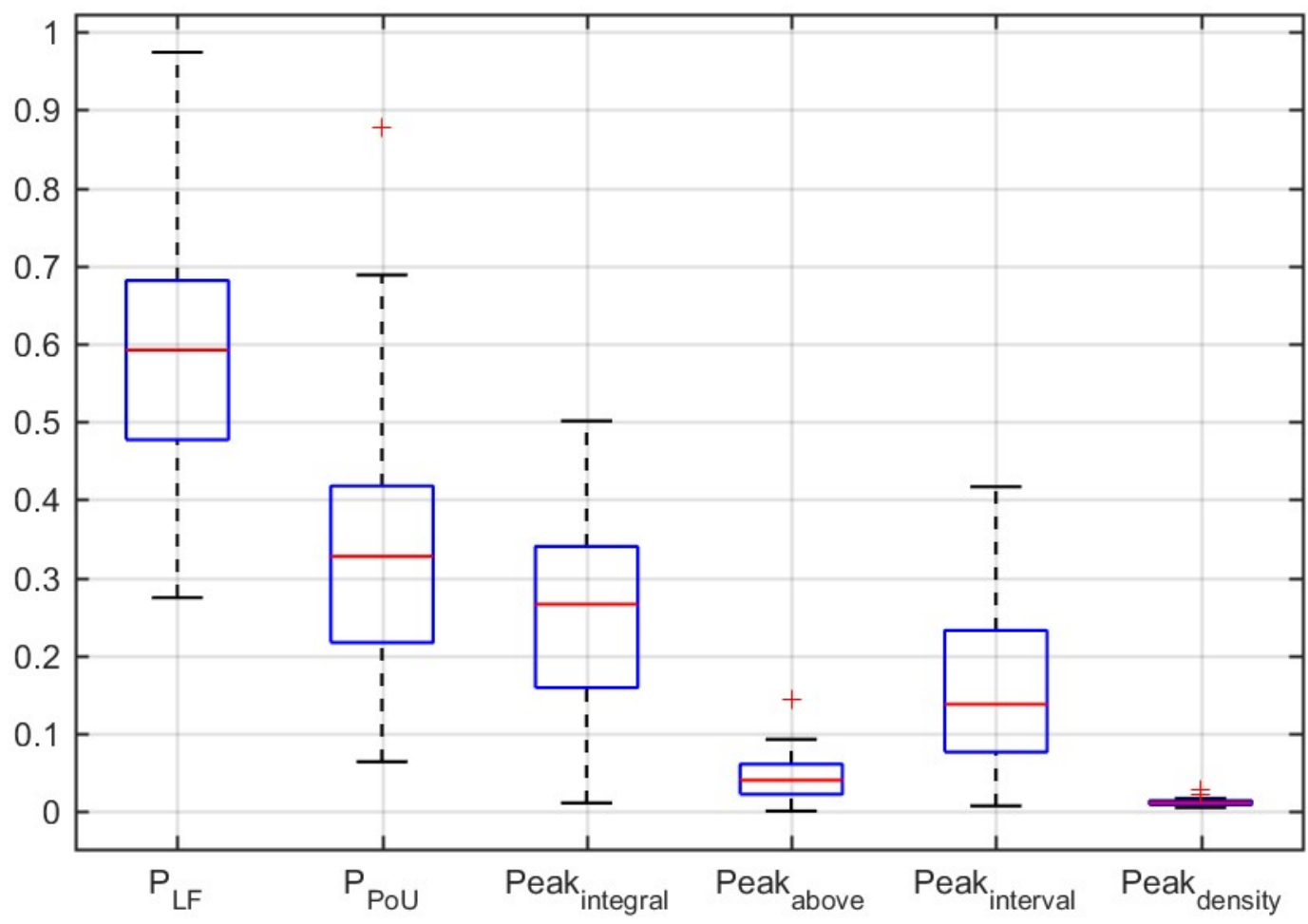

Figure 3: Box plot of load indicators

12 A more detailed explanation of the function can be found the Mathworks-homepage: https://de.mathworks.com/help/stats/stepwisefit.html\#bq9x28h-1 (4th May 2018) 


\begin{tabular}{|c|c|c|c|c|c|c|c|c|c|c|}
\hline & $\mathrm{kW}$ & in MWh & in $\mathrm{kW}$ & - & & & & & & \\
\hline $\min$ & 33.8 & 52 & 12.4 & 14 & $27.4 \%$ & $6.4 \%$ & $1.08 \%$ & $0.04 \%$ & $0.71 \%$ & $0.50 \%$ \\
\hline $\max$ & 4717.6 & 22375 & 2654.0 & 96 & $97.4 \%$ & $87.8 \%$ & $50.10 \%$ & $14.43 \%$ & $41.65 \%$ & $2.82 \%$ \\
\hline mean & 570.1 & 2059 & 361.4 & 45 & $57.4 \%$ & $33.4 \%$ & $25.24 \%$ & $4.15 \%$ & $15.42 \%$ & $1.13 \%$ \\
\hline std & 996.1 & 4462 & 658.9 & 18 & $14.9 \%$ & $16.5 \%$ & $12.88 \%$ & $2.92 \%$ & $9.28 \%$ & $0.42 \%$ \\
\hline mode & 325.6 & 1252 & 215.4 & 35 & $71.1 \%$ & $44.0 \%$ & $34.07 \%$ & $5.17 \%$ & $23.37 \%$ & $0.99 \%$ \\
\hline
\end{tabular}

We evaluated the load profiles of 50 different companies. The focus of this study is on small-medium-sized companies (SME) in Germany. The data cover a variety of different sectors, such as hotels, metals refining or production of drop forgings, as indicated by the more detailed meta-data for 20 companies. The data cover the whole year of 2017 at 15 minutes resolution. We refer to the Appendix for a detailed overview of the companies and their load indicators. The sample companies show a variety of different load behaviours. The annual peak load ranges from $34 \mathrm{~kW}$ to $4718 \mathrm{~kW}$. From the mean of $570 \mathrm{~kW}$, a standard deviation of $996 \mathrm{~kW}$ and a mode of $326 \mathrm{~kW}$, we can observe that the distribution of the annual peak load of the 50 companies is skewed to the left. The same holds true for the annual energy consumption, $E_{t o t a l}$, and $P_{M D}$. Using the above introduced load indicators, we are able to compare the load profiles of the different companies. Figure 3 illustrates the box plot of the load indicators. It shows that for the sample of 50 companies the distributions of the load indicators are slightly skewed.

\subsection{Market data}

We considered the market prices of the year 2017. For the continuous intraday market and the day-ahead market, we used the prices accessible over the EPEX-Database. The intraday price represents the mean average price and the day-ahead price the market-clearing price. For the PCR-prices, we used the maximum price bid that was accepted. We extract he prices from the homepage of regelleistung.net, a cooperation of the German transmission service operators. The capacity price $p_{\text {peak }}$ is the mean price on the medium-voltage level in the German federal state of Baden-Württemberg. The capacity prices are separated by the yearly period of use of $2500 \mathrm{~h} / \mathrm{a}$. Because of modelling restrictions we consider the average price of $44.46 € / k W h a$, but mention that the price gap is significant ${ }^{13}$. The BSS price is assumed to be $800 € / k W h$. In order to analyse the potential from a macroeconomic point of view and in the context of ongoing discussions about costs and potentials of flexibility, the applied discount rate is $2 \%$.

\footnotetext{
${ }^{13}$ yearly period of use $<2500 \frac{h}{a^{\prime}}, p_{\text {peak }}=10.02 \frac{€}{k W h a}$ and yearly period of use $\geq 2500 \frac{h}{a^{\prime}}$ $p_{\text {peak }}=78,89 \frac{€}{k W h a}$
} 


\section{Results and discussion}

\subsection{A1: Optimizing with fixed capacity}

For A1, we analysed the net present value (NPV) of the different use cases with a fixed BSS capacity of 500 kWh and a maximum power capability of $500 \mathrm{~kW}^{14}$. Figure 4 depicts the NPVs of all 50 companies for the different use cases. The use cases are sorted from lowest to highest NPV. The graph shows that the BSS can only generate a positive NPV for the latter two use cases, U5 and U6. Nonetheless, this is not the case for roughly half of the companies. The different load profiles influence the NPV of the use cases with peak shaving. In the other use cases, U1, U3 and U4, the NPV is independent of the load profile. Figure 4 gives on overview of the results for the different use cases with a fixed battery capacity. It shows the mean and standard deviation for the NPV, cap aged, number of full cycle equivalents and the c-rate ${ }^{15}$ for all charging activities.

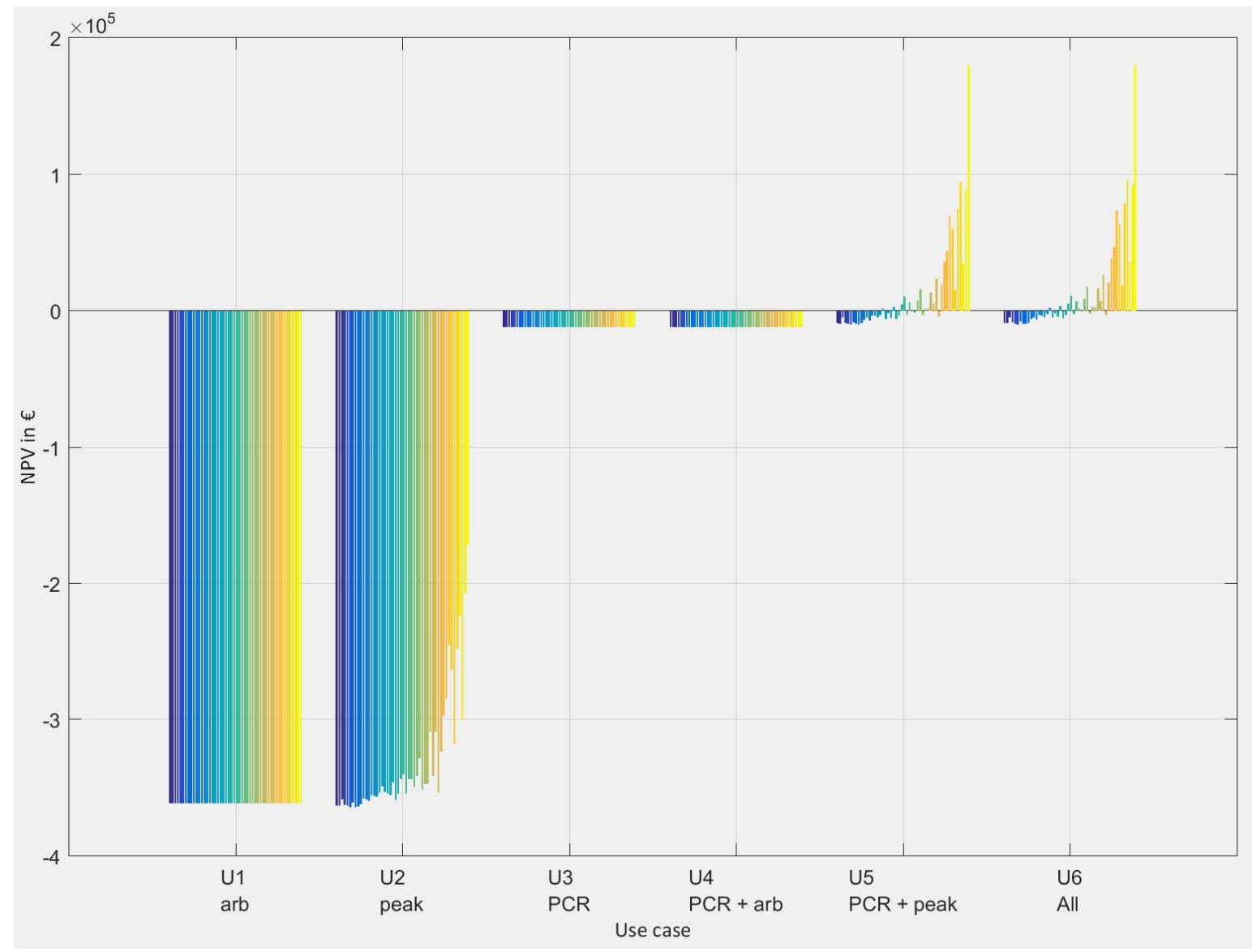

Figure 4: Bar chart of NPV of the different use cases for the 50 companies. The companies are arranged in ascending order referring to the yearly peak load.

\footnotetext{
${ }^{14} 500 \mathrm{kWh}$ and $500 \mathrm{~kW}$ represent the rounded mean value of the peak load of all 50 companies.

${ }^{15}$ The c-rate describes the rate at which a BSS charges or discharges (in kW) in relation to its capacity (in kWh), so for example a c-rate of 1 will deliver $100 \%$ of the BSS' capacity in one hour, and a c-rate of 2 in 0.5 hours etc.
} 
The use case with the lowest NPV is arbitrage trading and is the same for all 50 companies. This implies that the BSS only profits from price spreads on the energy markets by buying and selling on these markets and is not used to cover any part of the production load. The annual cash flow that the BSS generates through arbitrage trading sums up to $2019 €$. The BSS is charged during 144 time intervals and discharged during 181 intervals. This indicates that the BSS is utilized roughly $0.5 \%$ of the time. In contrast, the number of full cycle equivalents is 375 cycles, $9.3 \%$ of the cycle life of 4000 cycles, as the BSS charges and discharges with the maximum power capability to exploit the price spread on the market. The mean c-rate for all charging activities is 0.7542 . The constraints for battery degradation encourage the optimization model to keep the number of cycles to a minimum as well as the number of intervals with a high storage level. Avoiding a high number of cycles prolongs calendar life and reduces the investment. For the $U 1$, arbitrage trading, the low level of activity decreases the invested battery capacity, cap $_{a g e d}=$ $476 \mathrm{kWh}$. The reduced battery capacity is a result of the battery degradation constraint in equation (13) in subsection 3.1.3. For a profitable use case, the profit that can be generated on the energy market needs to be greater than the additional investment required to compensate battery degradation. For a battery price of $800 € / \mathrm{kWh}$, the price spread on the energy markets needs to be greater than $0.0759 € / \mathrm{kWh}^{16}$. This threshold would rise by $0.0069 € / \mathrm{kWh}$ for every time interval the storage level is not reduced. Additionally, the selling price needs to be at least 1.23 of the buying price to cover the electricity losses of the BSS.

The studies on the use cases with peak shaving, U2, show better NPVs, but a 500 kWh battery is not profitable even for the largest company. However, it is striking that the profitability of this use case strongly depends on the individual load profile of the companies. Conclusively, companies with a high peak load usually also have higher NPVs. The economic potential of peak shaving increases with the absolute peak load. For most of the companies on the other hand, a battery capacity of 500 kWh is disproportionately large and the cash flow through peak shaving never exceeds the investment in the BSS. In all cases, however, the battery is also used so little that capaged drops and has an average value of $468 \mathrm{kWh}$. The number of cycles and the c-rate can explain the great influence of the different load profiles on the profitability of the peak shaving use case. For example, the average number of cycles is 222 over the 11 years under consideration, but there is a large difference between the individual companies. Thus, Co50 has only 13 cycles, which is hardly more than 1 cycle per year, and a relatively high c-rate. Nevertheless, Co50 achieves the highest reduction in capacity prices. In contrast, the BSS of Co36 goes through 992 cycles over 11 years.

${ }^{16}$ The derived price spreads are a result of the partial derivative of equation (13) shown below:

$$
\begin{aligned}
& \frac{\mathrm{d} I n v_{B S S}}{d x_{B S S i n}}=\operatorname{cost}_{B S S} \cdot \frac{\mathrm{d} \text { cap }}{d x_{\text {agSin }}}=\operatorname{cost}_{B S S} \cdot\left(\frac{\mathrm{d} T L_{\text {redcal }}}{d x_{B S \operatorname{Sin}}}-\frac{d T L_{\text {redcycl }}}{d x_{B S \operatorname{Sin}}}\right) \\
& =\operatorname{cost}_{B S S} \cdot\left(\frac{0.3}{\Delta t}+\left(\frac{1}{3} \cdot \frac{T L_{c a l}}{T L_{c y c l}}\right)\right)=\frac{0.0069}{\Delta t} \frac{€ W h}{k W h}+0.0759 \frac{€}{k W h} \\
& \frac{\delta^{2} I n v_{B S S}}{\delta x_{B S \operatorname{Sin}} \cdot \delta t}=\frac{\frac{0.0069}{\Delta t} \frac{€}{\mathrm{kWh}}+0.0759 \frac{€}{\mathrm{kWh}}}{d t}=0.0069 \cdot \frac{€}{\mathrm{kWh} \cdot \text { time-interval }}
\end{aligned}
$$


Table 4: Results for the different use cases with a fixed BSS capacity

\begin{tabular}{|c|c|c|c|c|c|c|c|c|}
\hline & \multicolumn{2}{|c|}{ NPV } & \multicolumn{2}{|c|}{ cap $_{\text {aged }}$} & \multicolumn{2}{|c|}{ cycles } & \multicolumn{2}{|c|}{ c-rate } \\
\hline & mean & mean & mean & std & mean & std & mean & std \\
\hline & in $€$ & $\operatorname{in} €$ & in $k W h$ & in $\mathrm{kWh}$ & & & & \\
\hline$U 1$ & $-361,225$ & 0 & 476 & 0 & 375 & 0 & 0.7542 & 0.0000 \\
\hline$U 2$ & $-331,361$ & 44,662 & 468 & 11 & 222 & 250 & 0.0722 & 0.0960 \\
\hline$U 3$ & $-11,674$ & 0 & 586 & 0 & 9 & 0 & 0.0002 & 0.0000 \\
\hline$U 4$ & $-11,674$ & 0 & 586 & 0 & 9 & 0 & 0.0002 & 0.0000 \\
\hline U5 & 13,378 & 35,532 & 588 & 2 & 100 & 98 & 0.0011 & 0.0011 \\
\hline U6 & 14,486 & 36,069 & 590 & 4 & 156 & 141 & 0.0067 & 0.0061 \\
\hline
\end{tabular}

The values for the $U 3$ and $U 4$ are the same for all companies. This is because in both use cases the entire battery capacity is blocked for the provision of PCR. For all weeks in 2017, it is economically more attractive to offer PCR than to trade energy. Therefore, there is no possibility to use the battery for arbitrage trading. Of all revenue streams individually, PCR is the most profitable. However, on the PCR market, a $500 \mathrm{kWh}$ battery at a price of $800 € / \mathrm{kWh}$ will not produce a positive NPV. Even following two revenue streams in parallel, PCR and arbitrage, does not change the NPV. Overall, the battery is charged and discharged very lightly with regard to the number of cycles. Only nine additional full cycles are achieved in eleven years. Nevertheless, the battery capacity to be invested in has increased to $586 \mathrm{kWh}$, see Table 3, due to battery degradation, as the average charge level over the entire time is $50 \%$.

Only for the last two use cases, U5 and U6, can a positive NPV be observed, but not for all companies. Again, companies with relatively high peak load have higher NPVs than companies with a lower peak load. PCR is offered in all cases every week, but the amount of PCR offered varies weekly. This frees up battery capacity for either peak shaving, U5, or peak shaving and arbitrage trading, U6. Figure 4 shows that the combination of PCR and peak shaving has the greatest influence on the profitability of BSS. The addition of arbitrage trading can only positively influence the NPV in individual cases and only by a relatively small amount.

Considering the cap_aged, cycle number and c-rate, the observations for the single revenue stream use cases hold true for the parallel revenue streams as well. Combining peak shaving with PCR increases the average cycle number and average c-rate. Including arbitrage trading into the use cases increases these numbers even further. This in return leads to a higher degradation of the BSS and therefore in a higher capaged.

\subsection{A2: Optimizing with variable capacity}

For $A 2$, we run the model one more time for use case $U 6$. This time we include the option to determine $B S S_{c a p}$ endogenously. This allows us to consider the different production sizes of the 50 companies. Figure 5 shows the results of the model run for $U 6$ as a bar chart. The different colours in the bars indicate the proportion of the total 
cash flow that can be attributed to one of the three revenue streams, PCR, peak shaving and arbitrage trading. Furthermore, the black diamonds show the installed capacity of the BSS and is orientated at the right y-axis.

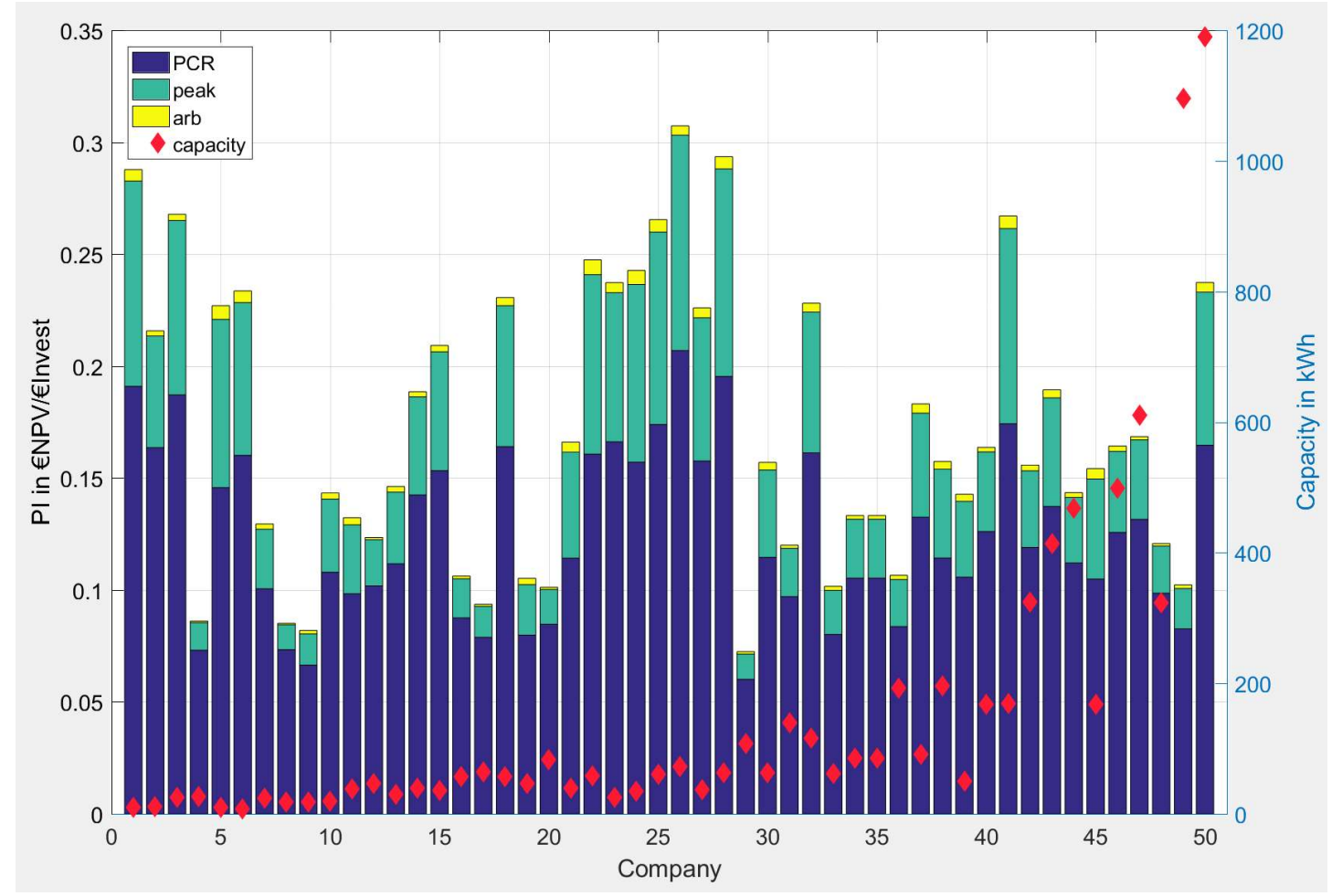

Figure 5: Results of U6 with variable BSS cap, PI for 50 companies ascending by peak load, divided into the share of the single revenue streams of the total cash flow

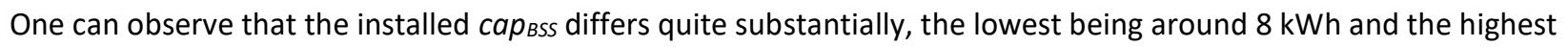
reaching close to $1200 \mathrm{kWh}$. For a better comparison, we show the profitability index, $\mathrm{PI}$, of the installed BSS of the different companies. For illustration, for company 49 and company 50 the model installs two large BSS, 1096 kWh and 1189 kWh respectively. Simultaneously, company 49 could reach with its BSS a PI of $0.1023 € / €$. Whereas company 50 reaches a $\mathrm{PI}$ of $0.2373 € / €$. Applying this to the rest of the sample companies, we detect that the $\mathrm{PI}$ seems independent from the model chosen capBS. In general, with a mean value of 0.1717 the overall level of PI seems very low. This is even more evident, once we consider the payback period (PP). The mean PP is reached after 8.4 years with a standard deviation of 0.45 years. This translates into a breakeven point after more than $75 \%$ of the BSS lifetime.

When we take a close look at the share of the single revenue streams of the total cash flow, we observe that arbitrage trading plays a minor role determining the PI of the BSS. The highest share is on the PCR revenue stream, mean of roughly $75 \%$, and then the peak shaving revenue stream, mean of roughly $24 \%$. Furthermore, we observe that the $\mathrm{PI}$ is increasing with a growing peak-share ${ }^{17}$. Figure 6 shows the scatter of PCR-share and peak-share to the PI. The

\footnotetext{
${ }^{17}$ The term peak-share refers to the share the peak shaving revenue stream provides to the cash flow. Respectively, PCR-share describes the share of the PCR revenue stream.
} 
least square fit lines indicate the trend of the relation between the revenue share and the PI. Both of the independent variable are highly correlated with the dependent variable PI. For the PCR-share the $R^{2}$ is 0.78 and for peakshare the $R^{2}$ is 0.83 . Additionally, we detect that the trend is almost complementary to 1 , which can be explained as arbitrage trading plays a minor role.

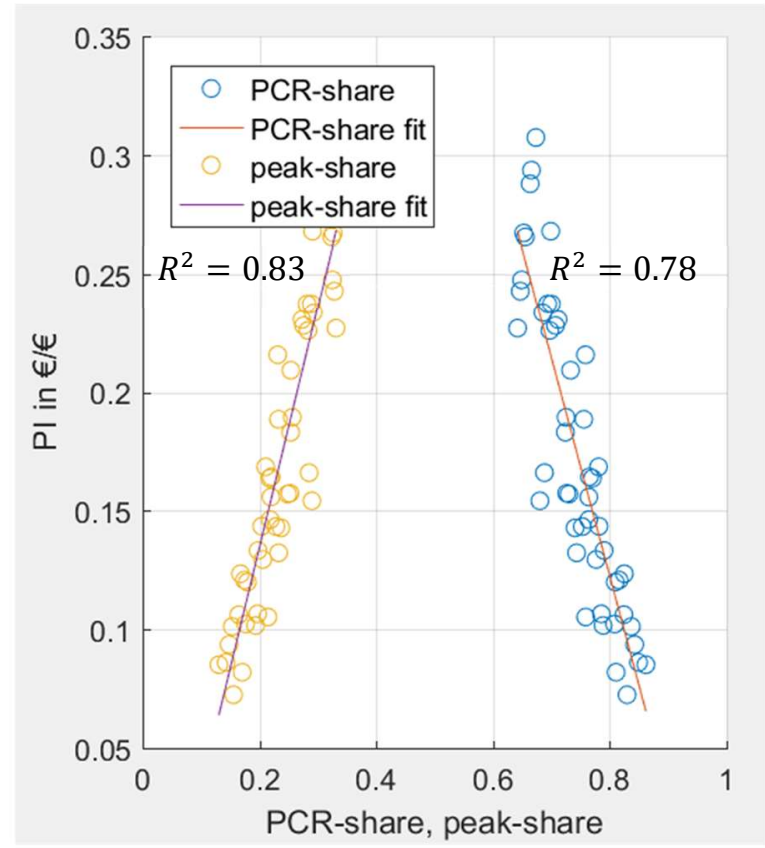

Figure 6: Scatter plot of PCR-share and peak-share to Pi including a least square fit line

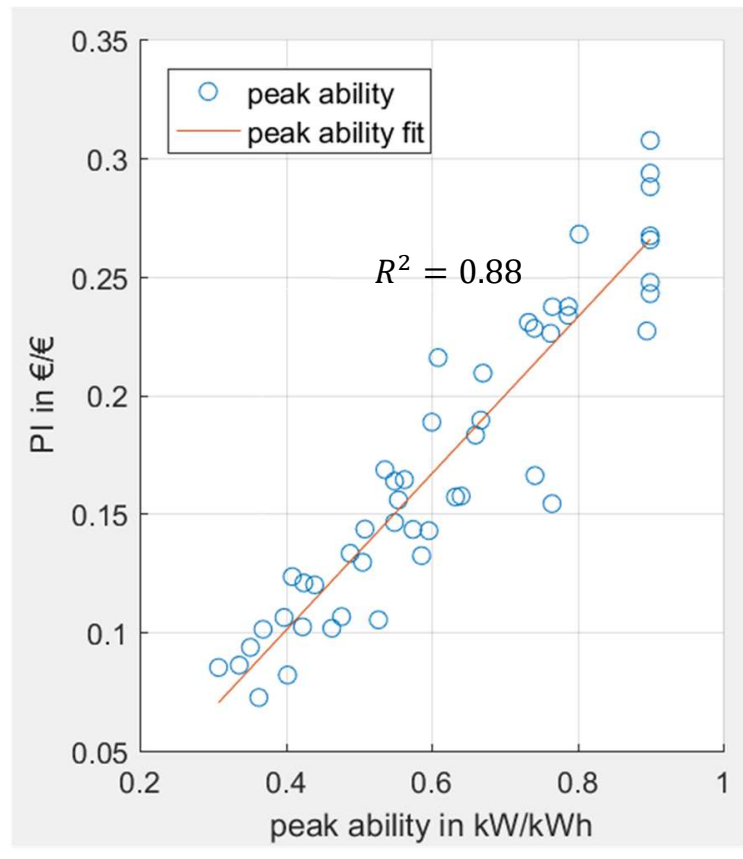

Figure 7: Scatter plot of Pi over peak ability with least square fit

To explain the economic potential for peak shaving in the different companies, we calculate the peak ability of the BSS, peak $k_{a b i l}$, shown in equation (41). This describes by how many kW every kWh of battery capacity installed reduces the original peak load. Figure 7 shows the scatter plot of PI over peakabil with a least square fit curve and a $R^{2} o f 0.88$.

$$
\text { peak }_{\text {abil }}=\frac{\text { Peak } k_{\text {max }, \text { old }}-\text { Peak } k_{\text {max }, \text { new }}}{\operatorname{cap}_{B S S}}
$$

This leads us to the conclusion that the profitability of a BSS mostly depends on the two revenue streams PCR and peak shaving. The higher the share of the total cash flow is due to peak shaving, the higher the overall profitability of the BSS investment. Therefore, the BSS that can utilize its capacity more efficiently than others to reduce the peak load is more likely to achieve a higher profitability. Still, the PCR and peak shaving revenue stream function complementarily. By itself under our assumed prices, one revenue stream cannot generate enough cash flow for the investment to break even. Our model finds for each company the optimal combination of how much capacity of the BSS to block for the PCR operation as to still generate enough revenue by peak shaving.

\subsection{A3: Stepwise linear regression of load characteristics}

In the analysis $A 3$, we develop a linear regression model to describe the relationship between load indicators and the model result, $\mathrm{PI}$, for all 50 companies. The load indicators are described in the section 3.3. 


\begin{tabular}{|l|l|l|l|l|}
\hline Step & adding/removing & Variable & FStat & pValue \\
\hline 1 & Adding & Peak $k_{\text {density }}$ & 7.14 & 0.0103 \\
\hline 2 & Adding & Peak $k_{\text {above }}$ & 10.68 & 0.0020 \\
\hline
\end{tabular}

Table 5 shows the steps of the stepwise linear regression analysis. The first variable that is added to describe the variance of $P I$ is the load indicator Peakdensity. In the second step, the variable Peakabove is added to the linear model to further increase the $R^{2}$ of the model. The stepwise analyses identifies no other variables to be significant, hence no further steps are needed to further add or remove variables from the linear model.

Equation (42) shows the derived linear regression model to describe the variation of $P I$. The ordinary $R^{2}$ of the model is 0.291 and the adjusted $R^{2}$ is 0.260 . This shows that the linear model has a moderate ability to describe the variance of PI. Both variables have a p-Value below 0.01 and therefore correlate significantly with PI. For a better illustration, we multiplied the load indicators by 100 as to represent a percentage of the total daily energy consumption. The estimated coefficient for Peakdensity is 0.0809 . If the other variable is held constant $P /$ would increase by $0.0809 € / €$ once Peakdensity is increased by 1 percentage point. Peak density is positive correlated with the dependent variable PI. On the contrary, if the other independent variable Peakabove is increased by 1 percent $P I$ decreases by $0.0156 € / €$ as they are negative correlated. Therefore, the contribution to the variance of $P I$ is higher for Peakdensity but for Peakabove it is more significant. The collinearity statistics in Table 6 show that the case of multi-collinearity does not need to be considered (tolerance $>0.25$ and VIF $<5.0$ ).

Table 6: Linear model statistics

\begin{tabular}{|c|c|c|c|c|c|c|}
\hline & & & & & \multicolumn{2}{|c|}{ Colinearity statsitics } \\
\hline & Estimate & SE & tStat & pValue & tolerence & VIF \\
\hline (Intercept) & 0.1451 & 0.0226 & 6.4281 & $<0.001$ & & \\
\hline Peak $k_{\text {density }}$ & 0.0809 & 0.0248 & 3.2680 & 0.0020 & 0.8185 & 1.22 \\
\hline Peak $k_{\text {above }}$ & -0.0156 & 0.0036 & -4.3585 & $<0.001$ & 0.8185 & 1.22 \\
\hline
\end{tabular}

The results are in line with the expectations. A higher value for Peak $k_{\text {density }}$ would imply that a greater amount of the daily energy consumption occurs during a peak period. Therefore, this could be an implication for a greater peak shifting potential where greater amounts of energy can be shifted easier to non-peak periods. On the other hand, a lower value for Peak $k_{\text {above }}$ implies that the amount of energy above the peak threshold, $\mathrm{P}_{M D}$, is smaller compared to the daily energy consumption. For example, this could occur in cases of single high peaks or constantly appearing smaller peaks. In either case, the amount of peak shaving energy would be decrease and the peak shaving potential of a small BSS would rise. 


\begin{tabular}{|c|c|}
\hline$P I=0.1451^{* * *}+0.0809^{* * *}$ Peak $k_{\text {Density }} \cdot 100-0.0156^{* * *}$ Peak $k_{\text {above }} \cdot 100$ & (42) \\
\hline$* p<0.1, \quad * * p<0.05, \quad{ }^{* * *} p<0.01$ \\
\hline
\end{tabular}

\subsection{Sensitivities}

The model results are considerably sensitive to variations in battery price, lifetime of the BSS and assumed discount rate. With decreasing battery prices the model choses to install larger BSS capacities. Below a certain battery price, around $780 € / \mathrm{kWh}$, the installed capacity abruptly increases from values smaller than $2 \mathrm{MWh}$ to the maximum value possible of $10 \mathrm{MWh}$. This sudden increase also appears with decreasing discount rate, at about $1.5 \%$, which can be seen in Figure 8, and an increasing battery life, at around 5000 cycles $^{18}$. Furthermore, the sudden increase indicates a state where the installation of a BSS for PCR by itself is already profitable. As the PCR revenue stream is independent of individual load profiles the model chooses for every company the maximum capacity. Simultaneously, Figure 8 shows that the installed battery capacity drops exponentially with an increasing discount rate and approaches zero. Figure 8 depicts model results for the installed battery capacity, $c a p_{B S S}$, as a mean value over all companies with varying discount rate.

Considering the results, for many companies a BSS is barely profitable. Therefore, changes in the PCR-prices and the

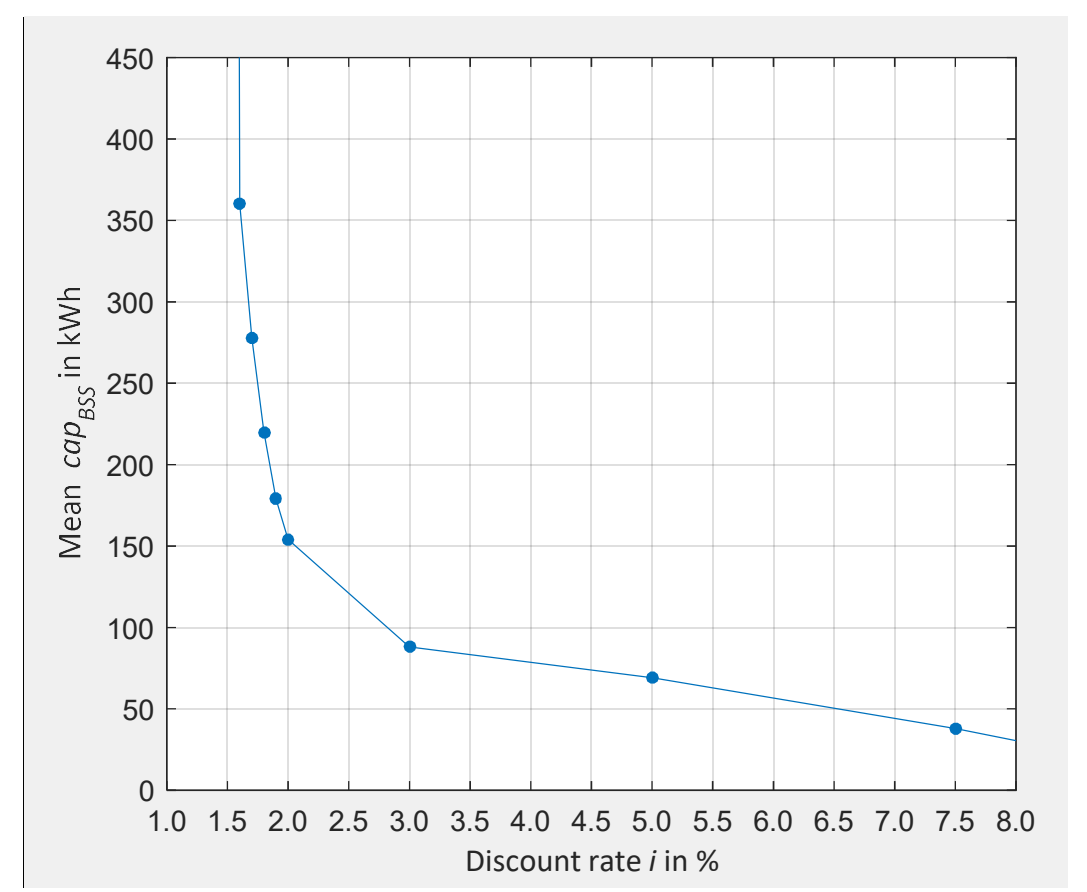

Figure 8: Sensitivity analysis for varying discount rate. Shown are the results for the mean installed battery capacity, $\operatorname{cap}_{B S S}$. (The line between the points is for graphical understanding only and does not refer to model results.)

capacity prices have a strong effect on the installed BSS-capacity. Current price trends on the PCR-market imply a lower price level than in 2017 while capacity prices have been increasing over the past years. Additionally, capacity

\footnotetext{
${ }^{18}$ The influence of varying calendar life cannot be properly assessed as the constraints in equation (13) and (15) underestimate respectively overestimates the battery degradation in case the assumed technology life differs from the calendar life.
} 
prices vary significantly among the different regions in Germany. On average, the northern parts of Germany have capacity prices three times as high as southern Germany. The local differences are even more extreme, as the highest price amounts to six times the lowest price [64]. For most companies, rising PCR-prices would lead to greater amounts of the capacity blocked for PCR-provision. Accordingly, rising capacity prices would lead to a higher peakshare and vice versa. Furthermore, with rising capacity prices one could observe a greater divergence between the PI of the different companies due to the load profile dependency. Eventually, how these price changes would vary the profitability of the BSS, still depends on the peak potential of the individual company, the correlation of the PCRprice-profile and the individual load-profile and the relationship of the PCR-price level and the capacity price-level.

\subsection{Critical reflection}

This section provides a brief critical reflection on the developed approach and assumptions. Attention is firstly turned to the developed model, which is a deterministic optimization under perfect foresight for a representative year. This approach furthermore assumes a predictable load and $100 \%$ acceptance of price bids on all three markets, and the year 2017 is assumed a representative year for the lifetime of the BSS. Hence, there is a significant level of uncertainty associated with future developments in load profiles and market prices, neither of which are well captured in the model. The load profiles are based on a sample with a limited amount of metadata, which makes it difficult to infer the importance of sample bias. In addition, the system boundary for the analysis is at the company level. Implicitly, we assume that an aggregator is able to pool the required BSS capacities to trade on the respective markets. The associated costs of which are neglected. Furthermore, the assumed discount rate of $2 \%$ depicts a macroeconomic social discount rate. The discount rate employed by the individual company might be much higher, which would further decrease the profitability of investment. Whilst the reported sensitivity analysis indeed goes some way to exploring the impacts of different assumptions on the profitability of different business cases, this uncertainty cannot be eliminated and the results should therefore be interpreted in this context.

The intraday market might hold higher potential for arbitrage trading than displayed in this paper as prices change dynamically. In this paper, only the weighted average and no order book price data have been applied. The model therefore limits the number of trades on the intraday market to one per product disregarding for reasons of long runtimes the potential that lies in dynamic asset-backed trading. Furthermore, the analysis neglects any feedback effects of the BSS optimisation: the PCR market has a total volume of $1378 \mathrm{MW}^{19}$, so if the 50 SMEs were to install the maximum capacity of $10 \mathrm{MWh}$ combined they would be able to offer around $333 \mathrm{MW}$ of PCR. The ensuing market saturation would probably result in much lower prices and therefore less favourable economic conditions. Additionally, future market changes will have an influence on the potential of parallel revenue streams for the BESS. For example, the product duration of PCR will decrease from 7 days to 1 day in November 2018 and 4 h products in July 2020 [66], which will increase the flexibility for companies to switch between possible revenue streams.

19 The mean value per week of the required primary control reserve in 2017 ([65]) 
Other weaknesses relate the technology of the BSS itself, especially the model constraints to depict battery degradation. Current studies from battery testing of electric vehicles indicate at least double the life duration than we considered [67]. Additionally, the influence of the c-rate, depth of discharge and the temperature on the degradation process $[51,68,69]$ is not included in the model. On the other hand, the observed c-rates are low. Thus, the influence might be negligible. For our model, we assume a battery control system that is capable of implementing the advised dispatch plan. Additional cost for such a management system is not included. Finally, the reliability of the battery is not considered, which would have important implications for the production process. We have assumed that the BSS is a pseudo-flexibility, in that it does not interfere with the production process directly. But cost savings through peak shaving need to outweigh production uncertainties. Especially in SMEs, the production is more volatile and order-dependent than in energy-intensive industries. So analysing the implications of lower BSS reliabilities should be covered by future work.

Finally, future research needs to extend the linear regression model to make it more robust. Results from sensitivity analyses, like the variation of the ratio between the PCR and capacity price level, should be included. The choice of $P_{M D}$ as the threshold for peak definition is useful as it allows for comparability between different load profiles. For a better understanding of the peak shaving potential, the definition of a peak needs to be explored further and the scope of the load profile data extended.

\section{Summary and conclusion}

Increasing fractions of renewable electricity generation require more flexibility within the energy system, especially on the demand side. Against this background, this paper has developed and applied an optimization model to assess the profitability of different parallel revenue streams for a battery storage system (BSS) in industrial companies. By not interfering with the production process, the BSS provides a pseudo-flexibility with significant advantages compared to other intrusive DSM measures. The linear program (LP) with 15-minute resolution optimizes the capacity of a BSS by maximising the Net Present Value (NPV) across the operational lifetime. In contrast to existing contributions, the BSS is employed for one or more revenue streams in parallel, including arbitrage trading, power control reserve (PCR) and peak shaving. The novelty of the approach lies in this combination of revenue streams, which especially due to the quite different market requirements and timeframes is challenging to model. A final step involves a stepwise linear regression of the profitability in relation to newly-defined load indicators.

The model is applied to a set of 50 German small and medium enterprises (SMEs), based on empirical data for these companies. The results show that, under the default assumptions, neither of these three business cases is economically attractive (i.e. negative NPVs) individually. When combined, the most profitable business model is achieved with all revenue streams (positive NPVs). Hence, with a fixed BSS capacity of $500 \mathrm{kWh}$, the Net Present Value (NPV) varies from a minimum of $-350,000 €$ for just arbitrage up to about $200,000 €$ for all three use cases in parallel. In the case of a variable BSS capacity, this varies up to $1200 \mathrm{kWh}$ and the Profitability Index (the ratio of investment to NPV) varies from 0.06 to 0.31 . The profitability can be attributed mostly to the cash flow from peak shaving and PCR. Under current market conditions, arbitrage trading contributes marginally to the profitability as the price spreads on the energy markets are too small to justify stronger battery degradation. There is a large variation in profitability between the 
companies in terms of the profitability and the size of the battery installed, both of which are closely related to the characteristics of the electrical load profile. The stepwise linear regression reveals a moderate dependency of the BSS profitability on the two newly developed indicators Peak density and Peakabove. The profitability of the BSS is strongly affected by the techno-economic assumptions, for example the BSS capacity suddenly increases from below 2 MWh up to the maximum possible value of $10 \mathrm{MWh}$ with battery prices below $780 € / \mathrm{kWh}$, interest rates below $1.5 \%$ and more than 5000 remaining cycles.

The developed approach is subject to considerable uncertainties relating to the future development of load profiles, market frameworks and technology costs, which should all be borne in mind when interpreting the results. Furthermore, the microeconomic perspective adopted in this work does not consider the feedback effects that individual SMEs investing in BSSs would have on the PCR markets. In the extreme case, these markets could become completely saturated, thereby negating any apparent economic potential shown here. Future work should therefore especially focus on a more detailed depiction of the BSS's technical behaviour, including degradation and reliability, as well on developing more robust statistical relationships between load indicators, based on larger samples, and profitability.

\section{Acknowledgement}

The authors thank the Energie Consulting GmbH in Kehl-Goldscheuer, Germany, and its managing director Dr. Jürgen Joseph for the provision of the anonymized data of the 50 SMEs.

\section{Notes}

The authors declare no competing interests.

\section{References}

[1] Bolay S, Bullmann T, Hegner M. Faktenpapier Energiespeicher: Rechtsrahmen, Geschäftsmodelle, Forderungen; 2016.

[2] Jochem P, Kaschub T, Fichtner W. How to Integrate Electric Vehicles in the Future Energy System? In: Hülsmann M, Fornahl D, editors. Evolutionary Paths Towards the Mobility Patterns of the Future. Berlin, Heidelberg: Springer Berlin Heidelberg; 2014, p. 243-263.

[3] Rodríguez-García J, Álvarez-Bel C, Carbonell-Carretero J-F, Alcázar-Ortega M, Peñalvo-López E. A novel tool for the evaluation and assessment of demand response activities in the industrial sector. Energy 2016;113:113646.

[4] Atabay D, Dornmair R, Hamacher T, Keller F, Reinhart G. Flexibilisierung des Stromverbrauchs in Fabriken. Graz/Austria; 2014.

[5] Schultz C, Sellmaier P, Reinhart G. An Approach for Energy-oriented Production Control Using Energy Flexibility. Procedia CIRP 2015;29:197-202.

[6] Shoreh MH, Siano P, Shafie-khah M, Loia V, Catalão JPS. A survey of industrial applications of Demand Response. Electric Power Systems Research 2016;141:31-49. 
[7] Thielmann A, Sauer A, Wietschel M. Produkt-Roadmap Stationäre Energiespeicher 2030. Karlsruhe; 2015.

[8] Gallo AB, Simões-Moreira JR, Costa HKM, Santos MM, Moutinho dos Santos E. Energy storage in the energy transition context: A technology review. Renewable and Sustainable Energy Reviews 2016;65:800-22.

[9] Reid G, Julve J. Second Life-Batteries as Felxible Sotrage for Renewables Energies; 2016.

[10] Eyer JM, Schoenung SM. Benefit/cost framework for evaluating modular energy storage: A study for the DOE energy storage systems program. Albuquerque; 2008.

[11] Shcherbakova A, Kleit A, Cho J. The value of energy storage in South Korea's electricity market: A Hotelling approach. Applied Energy 2014;125:93-102.

[12] Stephan A, Battke B, Beuse MD, Clausdeinken JH, Schmidt TS. Limiting the public cost of stationary battery deployment by combing applications. Nature Energy 2016;2016(Vol. 1).

[13] Lombardi P, Schwabe F. Sharing economy as a new business model for energy storage systems. Applied Energy 2017;188:485-96.

[14] Cho J, Kleit AN. Energy storage systems in energy and ancillary markets: A backwards induction approach. Applied Energy 2015;147:176-83.

[15] Moreno R, Moreira R, Strbac G. A MILP model for optimising multi-service portfolios of distributed energy storage. Applied Energy 2015;137:554-66.

[16] Dowling AW, Kumar R, Zavala VM. A multi-scale optimization framework for electricity market participation. Applied Energy 2017;190:147-64.

[17] Atabay D. An open-source model for optimal design and operation of industrial energy systems. Energy 2017;121:803-21.

[18] EPEX SPOT. Market data day-ahead auction: For the year 2017. [June 06, 2018]; Available from: https://www.epexspot.com/de/marktdaten/dayaheadauktion/chart/auction-chart/2017-12-31/DE.

[19] AG Energiebilanz. Energy consumption in Germany in 2017. Berlin, Bergheim; 2018.

[20] EPEX SPOT. Market data intraday auction: For the year 2017. [June 06, 2018]; Available from: https://www.epexspot.com/de/marktdaten/intradaycontinuous/chart/intraday-chart/2017-12-31/DE.

[21] Graditi G, Ippolito MG, Telaretti E, Zizzo G. Technical and economical assessment of distributed electrochemical storages for load shifting applications: An Italian case study. Renewable and Sustainable Energy Reviews 2016;57:515-23.

[22] Lin B, Wu W. Economic viability of battery energy storage and grid strategy: A special case of China electricity market. Energy 2017;124:423-34.

[23] Sandoval D, Leibundgut H. Introduction of electrical batteries in the operation of LowEx buildings. Energy and Buildings 2014;81:105-14.

[24] Bradbury K, Pratson L, Patiño-Echeverri D. Economic viability of energy storage systems based on price arbitrage potential in real-time U.S. electricity markets. Applied Energy 2014;114:512-9.

[25] Heymans C, Walker SB, Young SB, Fowler M. Economic analysis of second use electric vehicle batteries for residential energy storage and load-levelling. Energy Policy 2014;71:22-30. 
[26] Zheng M, Meinrenken CJ, Lackner KS. Agent-based model for electricity consumption and storage to evaluate economic viability of tariff arbitrage for residential sector demand response. Applied Energy 2014;126:297306.

[27] Faessler B, Kepplinger P, Petrasch J. Decentralized price-driven grid balancing via repurposed electric vehicle batteries. Energy 2017;118:446-55.

[28] Jiang DR, Powell WB. Optimal Hour-Ahead bidding in the real-time elictricity market with battery storage using approximate dynamic programming. INFORMS Journal on Computing 2015;2015(Vol. 27, No. 3):525-43.

[29] Hollinger R, Cortés AM, Erge T, Engel B. Analysis of the minimum activation period of batteries in frequency containment reserve. In: 2017 14th International Conference on the European Energy Market (EEM); 2017, p. $1-6$.

[30] Deutsche ÜNB. Prequalified Capacity in Germany. [August 06, 2018]; Available from: https://www.regelleistung.net/ext/download/pq_capacity.

[31] Ding D, Li JL, Yang SL, Wu XG, Liu ZQ. Capacity Configuration of BESS as an Alternative to Coal-Fired Power Units for Frequency Control. Advanced Materials Research 2014;953-954:743-7.

[32] Kunisch HJ, Kramer KG, Dominik H. Battery Energy Storage Another Option for Load-Frequency-Control and Instantaneous Reserve. IEEE Transactions on Energy Conversion 1986;EC-1(3):41-6.

[33] Taylor PA. Update on the Puerto Rico electric power authority's spinning reserve battery system. In: Proceedings of 11th Annual Battery Conference on Applications and Advances; 1996, p. 249-252.

[34] Joseph A, Shahidehpour M. Battery storage systems in electric power systems. In: Power Engineering Society General Meeting, 2006. IEEE: IEEE; 2006, 8-pp.

[35] Doughty DH, Butler PC, Akhil AA, Clark NH, Boyes JD. Batteries for Large-Scale Stationary Electrical Energy Storage. The Electrochemical Society Interface 2010;19(3):49-53.

[36] Nykvist B, Nilsson M. Rapidly falling costs of battery packs for electric vehicles. Nature Climate Change 2015;5:329 EP -.

[37] Anderson D. An evaluation of current and future costs for lithium-ion batteries for use in electrified vehicle powertrains 2009.

[38] Deutsche ÜNB. Anforderungen an die Speicherkapazität bei Batterien für die Primärregelleistung; 2015.

[39] Deutsche ÜNB. Eckpunkte und Freiheitsgrade bei Erbringung von Primärregelleistung: Leitfaden für Anbieter von Primärregelleistung; 2014.

[40] Haberschusz D, Kwiecien M, Badeda J, Schulte D, Jöris F. Zwischenbericht Projekt BSMS; 2016.

[41] Senkel K. Wieviel Batteriegroßspeicher verträgt der Primärregelleistungsmarkt?; 2017; Available from: http://www.enervis.de/de/news-strommarkt/493-wieviel-batteriegrossspeicher-vertraegt-der-primaerregelleistungsmarkt. [January 03, 2018].

[42] Swierczynski M, Stroe DI, Stan Al, Teodorescu R, Lærke R, Kjær PC. Field tests experience from 1.6MW/400kWh Li-ion battery energy storage system providing primary frequency regulation service. In: IEEE PES ISGT Europe 2013; 2013, p. 1-5. 
[43] Lei B, Li XR, Huang JY, Tan SJ. Droop Configuration and Operational Mode Setting of Battery Energy Storage System in Primary Frequency Regulation. Applied Mechanics and Materials 2014;448-453:2235-8.

[44] Koller M, Borsche T, Ulbig A, Andersson G. Review of grid applications with the Zurich 1MW battery energy storage system. Electric Power Systems Research 2015;120(Supplement C):128-35.

[45] Fleer J, Stenzel P. Impact analysis of different operation strategies for battery energy storage systems providing primary control reserve. Energy Storage 2016;8:320-38.

[46] Hollinger R, Diazgranados LM, Wittwer C, Engel B. Optimal Provision of Primary Frequency Control with Battery Systems by Exploiting All Degrees of Freedom within Regulation. Energy Procedia 2016;99(Supplement C):20414.

[47] Malhotra A, Battke B, Beuse M, Stephan A, Schmidt T. Use cases for stationary battery technologies: A review of the literature and existing projects. Renewable and Sustainable Energy Reviews 2016;56:705-21.

[48] Telaretti E, Graditi G, Ippolito MG, Zizzo G. Economic feasibility of stationary electrochemical storages for electric bill management applications: The Italian scenario. Energy Policy 2016;94:126-37.

[49] Koller M, Borsche T, Ulbig A, Andersson G. Review of grid applications with the Zurich 1MW battery energy storage system. Electric Power Systems Research 2015;120:128-35.

[50] Martínez Ceseña EA, Good N, Mancarella P. Electrical network capacity support from demand side response: Techno-economic assessment of potential business cases for small commercial and residential end-users. Energy Policy 2015;82:222-32.

[51] Neubauer JS, Wood E, Pesaran A. A Second Life for Electric Vehicle Batteries: Answering Questions on Battery Degradation and Value. SAE Int. J. Mater. Manf. 2015;8(2).

[52] Zheng M, Meinrenken CJ, Lackner KS. Smart households: Dispatch strategies and economic analysis of distributed energy storage for residential peak shaving. Applied Energy 2015;147:246-57.

[53] Nottrott A, Kleissl J, Washom B. Energy dispatch schedule optimization and cost benefit analysis for grid-connected, photovoltaic-battery storage systems. Renewable Energy 2013;55:230-40.

[54] Chua KH, Lim YS, Morris S. Cost-benefit assessment of energy storage for utility and customers: A case study in Malaysia. Energy Conversion and Management 2015;106:1071-81.

[55] Park A, Lappas P. Evaluating demand charge reduction for commercial-scale solar PV coupled with battery storage. Renewable Energy 2017;108:523-32.

[56] Gitizadeh M, Fakharzadegan H. Battery capacity determination with respect to optimized energy dispatch schedule in grid-connected photovoltaic (PV) systems. Energy 2014;65:665-74.

[57] Brealey RA, Myers SC, Allen F. Principles of Corporate Finance. 10th ed.: McGraw-Hill/Irwin; 2011.

[58] Rominger J, Kern F, Schmeck H. Provision of frequency containment reserve with an aggregate of air handling units. Comput Sci Res Dev 2018;33(1-2):215-21.

[59] Deutsche ÜNB. Anforderungen an die Speicherkapazität beiBatterien für die Primärregelleistung; 2015.

[60] Kaschub T, Jochem P, Fichtner W. Solar energy storage in German households: Profitability, load changes and flexibility. Energy Policy 2016;98:520-32. 
[61] Lunz B, Yan Z, Gerschler JB, Sauer DU. Influence of plug-in hybrid electric vehicle charging strategies on charging and battery degradation costs. Energy Policy 2012;46:511-9.

[62] Bloom I, Potter BG, Johnson CS, Gering KL, Christophersen JP. Effect of cathode composition on impedance rise in high-power lithium-ion cells: Long-term aging results. Journal of Power Sources 2006;155(2):415-9.

[63] McLoughlin F, Duffy A, Conlon M. Evaluation of time series techniques to characterise domestic electricity demand. Energy 2013;50:120-30.

[64] Bundesnetzagentur. Monitoringbericht 2017. Bonn; 2017.

[65] Deutsche ÜNB. Tender overview. [August 07, 2018]; Available from: https://www.regelleistung.net/ext/tender/?lang=en.

[66] Deutsche ÜNB. TSOs' proposal for the establishment of common and harmonised rules and pro-cesses for the exchange and procurement of Balancing Capacity for Frequency Contain-ment Reserves (FCR) in accordance with Ar-ticle 33 of Commission Regulation (EU) 2017/2195 establishing a guideline on elec-tricity balancing; 2018.

[67] Werwitzke C. Neue Erkenntnisse zu Akku-Degradation bei Tesla-Autos. electrive.net 2018 , 16 April 2018; Available from: https://www.electrive.net/2018/04/16/neue-erkenntnisse-zu-akku-degradation-bei-tesla-autos/. [July 12,2018$]$.

[68] Han X, Ouyang M, Lu L, Li J. A comparative study of commercial lithium ion battery cycle life in electric vehicle: Capacity loss estimation. Journal of Power Sources 2014;268:658-69.

[69] Opitz A, Badami P, Shen L, Vignarooban K, Kannan AM. Can Li-Ion batteries be the panacea for automotive applications? Renewable and Sustainable Energy Reviews 2017;68:685-92. 


\section{Appendix}

\subsection{Model description}

In this section, we present the model equations. The essential equations are shown in section Methodology on page 8.

\subsubsection{Electricity flow balance constraints}

The production demand $\left(D_{\text {prod }}^{q, h, w}\right)$ can be either satisfied through electricity directly from the grid $\left(x_{g r i d, p r o d}^{q, h, w}\right)$ or electricity stored in the BSS $\left(x_{B S S, p r o d}^{q, h, w}\right)$, equation (43). As shown in equation (44), the electricity from the grid, $x_{g r i d}^{q, h, w}$, flows either to the BSS, $x_{\text {grid,BSS }}^{q, h, w}$, directly to the production, $x_{g r i d, p r o}^{q, h, w}$ or is fed into the grid from the BSS, $x_{B S S, g r i d}^{q, h, w}$. Furthermore, one part of $x_{\text {grid }}^{q, h, w}$ is traded on the dayhead market, $x_{\text {ahead }}^{h, w}$, the other on the intraday market, $x_{\text {intra }}^{q, h, w}$. Equation (45) shows the electricity balance for one hour.

\begin{tabular}{|ll|l|}
$D_{\text {prod }}^{q, h, w}=x_{B S S, \text { rod }}^{q, h, w}+x_{\text {grid,prod }}^{q, h, w}$ & $, x_{B S S, \text { rod }}^{q, h, w}, x_{\text {grid,prod }}^{q, h, w} \geq 0$
\end{tabular}

$$
x_{\text {grid }}^{q, h, w}=x_{\text {grid,BSS }}^{q, h, w}+x_{\text {grid,prod }}^{q, h, w}-x_{B S S, \text { grid }}^{q, h, w} \quad, x_{\text {grid,prod }}^{q, h, w}, x_{\text {grid,BSS }}^{q, h, w}, x_{B S S, \text { grid }}^{q, h, w} \geq 0
$$

$$
\sum_{q=1}^{4} x_{g r i d}^{q, h, w}=x_{\text {ahea }}^{h, w}+\sum_{q=1}^{4} x_{\text {intra }}^{q, h, w}
$$

\begin{tabular}{|c|c|}
\hline$x_{B S S, \text { in }}^{q, h, w}=\eta_{\text {in }} \cdot x_{\text {grid,BSS }}^{q, h, w}$ & (46) \\
\hline$x_{B S S, \text { out }}^{q, h, w}=\frac{1}{\eta_{\text {out }}} \cdot\left(x_{B S S, \text { grid }}^{q, h, w}+x_{B S S, \text { prod }}^{q, h, w}\right)$ & (47) \\
\hline
\end{tabular}

Equations (46) and (47) describe the electricity flow in, $x_{B S S, i n}^{q, h, w}$, and out, $x_{B S S, o u t}^{q, h, w}$, of the BSS. $x_{B S S, i n}^{q, h, w}$ combines $x_{g r i d, B S S}^{q, h, w}$ and $x_{P V, B S S}^{q, h, w}$ and multiplies the sum with an efficiency factor, $\eta_{i n}$, which considers the electricity losses of the charging process of the BSS. $x_{B S S, \text { out }}^{q, h, w}$ flows either back into the grid or to the production. In this case, an inverse efficiency factor, $\eta_{\text {out }}$, is considered. Equation (48) states that the maximum power capability of the BSS, $P c a p_{B S S^{20}}$, restricts the maximal electricity flow in and out of the BSS. The ratio between the power capability and the energy capacity of the BSS is set to 1 .

$$
x_{B S S, \text { out }}^{q, h, w}+x_{B S S, \text { in }}^{q, h, w} \leq \frac{P c a p_{B S S}}{4}
$$

${ }^{20}$ The term $\frac{\text { Pcap }}{4}$ converts power in $\mathrm{kW}$ into energy in kWh. 


\subsubsection{Battery constraints}

Equations (49) to (52) describe the storage level of the BSS , $l_{B S S}^{q, h, w}$, for every time interval. The level of the next period, $l_{B S S}^{q+1, h, w}$, equals the storage level of the current period, $l_{B S S}^{q, h, w}$, adjusted for self-discharge losses, $\left(1-d i s_{B S S}\right)$, combined with the electricity flowing in and out of the BSS until the next period. Equations (50) to (52) initialize the storage level for the beginning of every time level. Equation (50) shows that $l_{B S S}^{1, h, w}$, the storage level of the first period of the time level $h$ and $w$, refers to the storage level of the last period $(q=4)$ of the previous hourly time level $(h-1)$ for every $h \neq 1$ and $w \neq 1$. Accordingly (equation (51)), the first period of every week $w$ refers to the last period of the previous week $(w-1)$. Finally, equation (52) defines the circular definition of the time levels. To define the storage level of the first time period of the year, $l_{B S S}^{1,1,1}$, we refer to the last period of the year, $l_{B S S}^{4,168,52}$.

\begin{tabular}{|c|c|}
\hline$l_{B S S}^{q+1, h, w}=\left(1-d i s_{B S S}\right) \cdot l_{B S S}^{q, h, w}+x_{B S S, \text { in }}^{q+1, w}-x_{B S S, \text { out }}^{q+1, h \quad, \text { if } q \neq 1, h \neq 1 \text { and } w \neq 1}$ & (49) \\
\hline$l_{B S S}^{1, h, w}=\left(1-d i s_{B S S}\right) \cdot l_{B S S}^{4, h-1, w}+x_{B S S, \text { in }}^{1, h, w}-x_{B S S, \text { out }}^{1, h, w} \quad$, if $h \neq 1$ and $w \neq 1$ & (50) \\
\hline$l_{B S S}^{1,1, w}=\left(1-d i s_{B S S}\right) \cdot l_{B S S}^{4,168, w-1}+x_{B S S, \text { in }}^{1,1, w}-x_{B S S, \text { out }}^{1,1, w} \quad$,if $w \neq 1$ & (51) \\
\hline$l_{B S S}^{1,1,1}=\left(1-d i s_{B S S}\right) \cdot l_{B S S}^{4,168,52}+x_{B S S, \text { in }}^{1,1,1}-x_{B S S, \text { out }}^{1,1,1}$ & (52) \\
\hline
\end{tabular}

\subsection{Detailed load data}




\begin{tabular}{|c|c|c|c|c|c|c|c|c|c|c|}
\hline Company & peak load & $\begin{array}{l}\text { energy con- } \\
\text { sumption }\end{array}$ & $\mathbf{P}_{\mathrm{MD}}$ & $\mathbf{P}_{\text {ToU }}$ & $P_{L F}$ & $\mathbf{P}_{\text {PoU }}$ & Peak $_{\text {integral }}$ & Peak $_{\text {above }}$ & Peak $_{\text {interval }}$ & Peak $_{\text {density }}$ \\
\hline & kW & in $\mathrm{MWh}$ & in $\mathrm{kW}$ & - & & & & & & \\
\hline 1 & 33.8 & 153.88 & 25.5 & 37 & $69.5 \%$ & $52.2 \%$ & $1.08 \%$ & $0.05 \%$ & $0.71 \%$ & $0.71 \%$ \\
\hline 2 & 33.8 & 152.71 & 25.5 & 14 & $68.5 \%$ & $51.7 \%$ & $4.01 \%$ & $0.23 \%$ & $3.03 \%$ & $0.63 \%$ \\
\hline 3 & 35.8 & 51.76 & 12.4 & 34 & $54.0 \%$ & $16.6 \%$ & $12.13 \%$ & $2.21 \%$ & $7.08 \%$ & $0.81 \%$ \\
\hline 4 & 37.6 & 163.44 & 26.1 & 91 & $71.7 \%$ & $49.8 \%$ & $4.47 \%$ & $0.47 \%$ & $3.67 \%$ & $0.59 \%$ \\
\hline 5 & 39.3 & 70.29 & 23.8 & 31 & $32.1 \%$ & $20.5 \%$ & $25.18 \%$ & $3.26 \%$ & $10.69 \%$ & $1.60 \%$ \\
\hline 6 & 41.2 & 236.98 & 35.7 & 80 & $76.1 \%$ & $65.9 \%$ & $1.53 \%$ & $0.04 \%$ & $1.18 \%$ & $0.65 \%$ \\
\hline 7 & 43.7 & 104.88 & 22.5 & 35 & $53.3 \%$ & $27.5 \%$ & $9.49 \%$ & $1.34 \%$ & $6.49 \%$ & $0.82 \%$ \\
\hline 8 & 46.2 & 225.74 & 36.6 & 77 & $70.6 \%$ & $55.9 \%$ & $11.09 \%$ & $0.71 \%$ & $8.59 \%$ & $0.58 \%$ \\
\hline 9 & 54.4 & 154.15 & 29.0 & 37 & $63.1 \%$ & $32.4 \%$ & $35.37 \%$ & $5.59 \%$ & $25.26 \%$ & $1.03 \%$ \\
\hline 10 & 60.1 & 208.42 & 39.2 & 57 & $62.5 \%$ & $39.7 \%$ & $26.29 \%$ & $3.22 \%$ & $18.19 \%$ & $0.99 \%$ \\
\hline 11 & 73.3 & 59.50 & 26.2 & 31 & $28.8 \%$ & $9.3 \%$ & $22.10 \%$ & $6.37 \%$ & $7.84 \%$ & $1.40 \%$ \\
\hline 12 & 75.6 & 305.86 & 47.0 & 26 & $74.7 \%$ & $46.3 \%$ & $6.48 \%$ & $0.60 \%$ & $5.19 \%$ & $0.50 \%$ \\
\hline 13 & 82.0 & 201.75 & 44.0 & 38 & $57.4 \%$ & $28.2 \%$ & $26.87 \%$ & $5.02 \%$ & $15.80 \%$ & $1.09 \%$ \\
\hline 14 & 83.5 & 157.53 & 44.0 & 36 & $39.7 \%$ & $21.6 \%$ & $23.41 \%$ & $3.96 \%$ & $12.43 \%$ & $1.32 \%$ \\
\hline 15 & 88.7 & 167.85 & 42.8 & 39 & $51.8 \%$ & $21.7 \%$ & $27.58 \%$ & $4.31 \%$ & $14.11 \%$ & $1.41 \%$ \\
\hline 16 & 102.8 & 293.79 & 52.6 & 36 & $65.6 \%$ & $32.7 \%$ & $45.75 \%$ & $7.70 \%$ & $34.95 \%$ & $1.13 \%$ \\
\hline 17 & 104.7 & 205.78 & 54.1 & 46 & $42.1 \%$ & $22.5 \%$ & $23.97 \%$ & $4.46 \%$ & $13.06 \%$ & $0.98 \%$ \\
\hline 18 & 106.0 & 239.84 & 55.5 & 44 & $44.0 \%$ & $25.9 \%$ & $23.17 \%$ & $2.63 \%$ & $13.97 \%$ & $1.42 \%$ \\
\hline 19 & 107.1 & 107.54 & 44.0 & 45 & $32.4 \%$ & $11.5 \%$ & $21.76 \%$ & $6.66 \%$ & $7.26 \%$ & $1.56 \%$ \\
\hline 20 & 114.1 & 378.70 & 66.9 & 65 & $69.2 \%$ & $38.0 \%$ & $33.54 \%$ & $3.66 \%$ & $23.06 \%$ & $1.05 \%$ \\
\hline 21 & 115.1 & 229.95 & 62.9 & 35 & $47.7 \%$ & $22.9 \%$ & $15.87 \%$ & $2.00 \%$ & $7.62 \%$ & $1.53 \%$ \\
\hline 22 & 117.2 & 131.41 & 55.5 & 32 & $32.6 \%$ & $12.8 \%$ & $22.68 \%$ & $3.95 \%$ & $7.78 \%$ & $2.19 \%$ \\
\hline 23 & 120.3 & 382.24 & 78.3 & 50 & $59.6 \%$ & $36.4 \%$ & $39.31 \%$ & $5.65 \%$ & $24.12 \%$ & $1.14 \%$ \\
\hline 24 & 124.0 & 261.86 & 54.6 & 20 & $63.0 \%$ & $24.2 \%$ & $26.96 \%$ & $4.07 \%$ & $16.75 \%$ & $1.02 \%$ \\
\hline 25 & 164.5 & 380.79 & 71.7 & 35 & $61.1 \%$ & $26.5 \%$ & $13.45 \%$ & $2.30 \%$ & $10.33 \%$ & $0.65 \%$ \\
\hline
\end{tabular}




\begin{tabular}{|c|c|c|c|c|c|c|c|c|c|c|}
\hline Company & peak load & $\begin{array}{l}\text { energy con- } \\
\text { sumption }\end{array}$ & $\mathbf{P}_{\mathrm{MD}}$ & $\mathbf{P}_{\text {ToU }}$ & $\mathbf{P}_{\mathrm{LF}}$ & $\mathbf{P}_{\mathrm{PoU}}$ & Peak $_{\text {integral }}$ & Peak $_{\text {above }}$ & Peak $_{\text {interval }}$ & Peak $_{\text {density }}$ \\
\hline & $\mathrm{kW}$ & in $\mathrm{MWh}$ & in $\mathrm{kW}$ & - & & & & & & \\
\hline 26 & 175.0 & 555.24 & 118.4 & 71 & $53.8 \%$ & $36.3 \%$ & $3.94 \%$ & $0.14 \%$ & $2.14 \%$ & $1.23 \%$ \\
\hline 27 & 181.0 & 582.75 & 116.6 & 34 & $58.6 \%$ & $36.9 \%$ & $30.25 \%$ & $3.89 \%$ & $20.17 \%$ & $1.13 \%$ \\
\hline 28 & 206.8 & 754.17 & 128.0 & 24 & $68.1 \%$ & $41.7 \%$ & $9.13 \%$ & $0.52 \%$ & $6.68 \%$ & $0.95 \%$ \\
\hline 29 & 208.4 & 178.30 & 70.3 & 47 & $30.3 \%$ & $9.8 \%$ & $18.97 \%$ & $6.08 \%$ & $7.43 \%$ & $1.37 \%$ \\
\hline 30 & 239.6 & 432.74 & 134.6 & 49 & $47.2 \%$ & $20.7 \%$ & $33.69 \%$ & $7.26 \%$ & $13.37 \%$ & $1.65 \%$ \\
\hline 31 & 252.0 & 811.47 & 152.2 & 44 & $61.5 \%$ & $36.9 \%$ & $33.98 \%$ & $4.47 \%$ & $24.01 \%$ & $0.97 \%$ \\
\hline 32 & 259.3 & 302.70 & 105.9 & 37 & $46.3 \%$ & $13.4 \%$ & $32.26 \%$ & $6.66 \%$ & $13.54 \%$ & $1.68 \%$ \\
\hline 33 & 291.0 & 620.54 & 149.8 & 33 & $55.2 \%$ & $24.4 \%$ & $34.84 \%$ & $7.41 \%$ & $18.15 \%$ & $1.26 \%$ \\
\hline 34 & 325.6 & 1251.54 & 215.4 & 47 & $71.1 \%$ & $44.0 \%$ & $34.07 \%$ & $5.17 \%$ & $23.37 \%$ & $0.99 \%$ \\
\hline 35 & 325.6 & 1251.54 & 215.4 & 47 & $71.1 \%$ & $44.0 \%$ & $34.07 \%$ & $5.17 \%$ & $23.37 \%$ & $0.99 \%$ \\
\hline 36 & 362.9 & 201.85 & 64.8 & 46 & $45.2 \%$ & $6.4 \%$ & $16.46 \%$ & $7.44 \%$ & $6.71 \%$ & $0.85 \%$ \\
\hline 37 & 369.0 & 1501.01 & 257.9 & 32 & $67.2 \%$ & $46.6 \%$ & $30.52 \%$ & $2.77 \%$ & $23.21 \%$ & $0.90 \%$ \\
\hline 38 & 391.0 & 584.33 & 172.8 & 35 & $52.4 \%$ & $17.1 \%$ & $25.32 \%$ & $4.99 \%$ & $11.94 \%$ & $1.45 \%$ \\
\hline 39 & 460.0 & 1552.15 & 319.5 & 36 & $61.6 \%$ & $38.6 \%$ & $46.00 \%$ & $8.04 \%$ & $26.68 \%$ & $1.23 \%$ \\
\hline 40 & 522.6 & 1494.29 & 313.0 & 35 & $52.4 \%$ & $32.7 \%$ & $30.73 \%$ & $4.71 \%$ & $20.75 \%$ & $1.02 \%$ \\
\hline 41 & 674.0 & 2106.19 & 414.1 & 39 & $58.8 \%$ & $35.8 \%$ & $20.50 \%$ & $2.30 \%$ & $15.16 \%$ & $1.11 \%$ \\
\hline 42 & 1136.0 & 2720.36 & 665.7 & 54 & $52.8 \%$ & $27.4 \%$ & $43.64 \%$ & $8.88 \%$ & $22.49 \%$ & $1.36 \%$ \\
\hline 43 & 1252.0 & 4516.04 & 834.6 & 96 & $59.8 \%$ & $41.3 \%$ & $11.80 \%$ & $1.01 \%$ & $8.70 \%$ & $1.10 \%$ \\
\hline 44 & 1422.0 & 6342.18 & 961.5 & 96 & $74.1 \%$ & $51.1 \%$ & $27.25 \%$ & $2.34 \%$ & $24.46 \%$ & $0.77 \%$ \\
\hline 45 & 1524.0 & 1686.27 & 911.4 & 41 & $27.4 \%$ & $12.7 \%$ & $50.04 \%$ & $14.43 \%$ & $11.91 \%$ & $2.82 \%$ \\
\hline 46 & 1793.5 & 6309.87 & 1206.8 & 41 & $63.2 \%$ & $40.3 \%$ & $32.81 \%$ & $4.25 \%$ & $21.40 \%$ & $1.10 \%$ \\
\hline 47 & 2797.6 & 16819.08 & 2156.4 & 61 & $88.8 \%$ & $68.8 \%$ & $43.36 \%$ & $2.87 \%$ & $41.65 \%$ & $0.74 \%$ \\
\hline 48 & 2916.8 & 22375.17 & 2630.4 & 64 & $97.4 \%$ & $87.8 \%$ & $30.03 \%$ & $0.81 \%$ & $29.81 \%$ & $0.54 \%$ \\
\hline 49 & 3698.4 & 9171.24 & 2024.7 & 27 & $52.9 \%$ & $28.4 \%$ & $50.10 \%$ & $9.24 \%$ & $30.12 \%$ & $1.25 \%$ \\
\hline 50 & 4717.6 & 13797.35 & 2654.0 & 37 & $62.1 \%$ & $33.5 \%$ & $34.75 \%$ & $6.07 \%$ & $24.73 \%$ & $1.03 \%$ \\
\hline
\end{tabular}

